\title{
Loss of epidermal Evi/Wls results in a phenotype resembling psoriasiform dermatitis
}

\author{
Iris Augustin, ${ }^{1,3}$ Julia Gross, ${ }^{1,3}$ Daniel Baumann,, ${ }^{1,3}$ Claudia Korn, ${ }^{2}$ \\ Grainne Kerr, ${ }^{1,3}$ Tamara Grigoryan, ${ }^{5}$ Cornelia Mauch, ${ }^{4}$ Walter Birchmeier, ${ }^{5}$ \\ and Michael Boutros ${ }^{1,3}$ \\ 'Division of Signaling and Functional Genomics and 'Division of Vascular Oncology and Metastasis, German Cancer Research \\ Center (DKFZ), D-69120 Heidelberg, Germany \\ ${ }^{3}$ Department of Cell and Molecular Biology, Medical Faculty Mannheim, Heidelberg University, D-69120 Heidelberg, Germany \\ ${ }^{4}$ Department of Dermatology and Venereology, University of Cologne, D-50937 Cologne, Germany \\ ${ }_{5}^{5}$ Max-Delbrück Center for Molecular Medicine (MDC), D-13125 Berlin, Germany
}

Cells of the epidermis renew constantly from germinal layer stem cells. Although epithelial cell differentiation has been studied in great detail and the role of Wnt signaling in this process is well described, the contribution of epidermal Wnt secretion in epithelial cell homeostasis remains poorly understood. To analyze the role of Wnt proteins in this process, we created a conditional knockout allele of the Wnt cargo receptor Evi/Gpr177/Wntless and studied mice that lacked Evi expression in the epidermis. We found that K14-Cre, Evi-LOF mice lost their hair during the first hair cycle, showing a reddish skin with impaired skin barrier function. Expression profiling of mutant and wild-type skin revealed up-regulation of inflammation-associated genes. Furthermore, we found that Evi expression in psoriatic skin biopsies is down-regulated, suggesting that Evi-deficient mice developed skin lesions that resemble human psoriasis. Immune cell infiltration was detected in Evi-LOF skin. Interestingly, an age-dependent depletion of dendritic epidermal T cells (DETCs) and an infiltration of $\gamma \delta^{\text {low }}$ T cells in Evi mutant epidermis was observed. Collectively, the described inflammatory skin phenotype in Evi-deficient mice revealed an essential role of Wnt secretion in maintaining normal skin homeostasis by enabling a balanced epidermal-dermal cross talk, which affects immune cell recruitment and DETC survival.

\section{CORRESPONDENCE \\ Michael Boutros: \\ m.boutros@dkfz.de \\ $\mathrm{OR}$ \\ Iris Augustin: \\ i.augustin@dkfz.de}

Abbreviations used: DETC, dendritic epidermal T cell; EdU; (2'S)-2'-Deoxy-2'-fluoro-5ethynyluridine; TEC, thymic epithelial cell; TEWL, transepidermal water loss; TPA, 12-Otetradecanoylphorbol-13-acetate.
Inflammatory skin is the most common disorder in dermatology. Psoriasis and atopic dermatitis are the two main chronic conditions of inflammatory skin diseases and originate from an aberrant interaction between the skin and the immune system (Pittelkow, 2005). Characteristics of inflamed scaly skin are hyperproliferation and altered differentiation of keratinocytes, as well as increased inflammatory cell infiltration and blood vessel formation (Lowes et al., 2007; Wagner et al., 2010). Beyond environmental factors, a large set of hereditary factors, including many genes related to the immune system, contribute to the onset of the disease (Nestle et al., 2009). Some alterations in genes related to proper skin barrier function like filaggrin have also been implicated (Proksch et al., 2008; Roberson and Bowcock, 2010). Deficiencies in physical, biochemical, or immunological compositions enable percutaneous penetration of chemicals and microbes, which promotes inflammation. In mice, transgenic studies addressed the contribution of key signaling pathways to model psoriatic skin, including STAT3, AP-1, TGF- $\beta$, NF- $\mathrm{kB}$, and VEGF pathways (Gudjonsson et al., 2007; Swindell et al., 2011). These genetic studies have yielded insights into the regulation of complex inflammatory circuits, contributed to unraveling molecular and cellular changes that are consistently detected in psoriatic plaques, and contributed to developing novel therapeutic strategies (Wagner et al., 2010).

The contribution of Wnt signaling to the pathogenesis of chronic inflammatory skin diseases has not been studied in great detail. A genetic link between pathological skin malformations

2013 Augustin et al. This article is distributed under the terms of an AttributionNoncommercial-Share Alike-No Mirror Sites license for the first six months after the publication date (see http://www.rupress.org/terms). After six months it is available under a Creative Commons License (Attribution-Noncommercial-Share Alike 3.0 Unported license, as described at http://creativecommons.org/licenses/by-nc-sa/3.o/). 
and components of the Wnt signaling pathway was reported for the Goltz-Gorlin syndrome (Grzeschik et al., 2007). The Goltz-Gorlin Syndrome is an X-linked dominant disorder caused by mutations in the PORCN gene, which encodes for the acyl-transferase Porcupine, a component of the Wnt signaling pathway. Porcupine is required for the palmitoylation of Wnt proteins in the ER, a necessary step in Wnt secretion. PORCN mutations cause hypoplastic, hyperpigmented skin as well as digital, ocular, and dental malformations (Lombardi et al., 2011; Liu et al., 2012). Similarly, two recent studies reported an upregulation of Wnt5A and differential expression of other Wnt pathway components in human psoriatic plaques (Gudjonsson et al., 2007; Reischl et al., 2007; Romanowska et al., 2009).

Wnt proteins are lipid modified in the Wnt-producing cell and require the cargo receptor Evi/Wls for exocytosis (Bänziger et al., 2006; Bartscherer et al., 2006; Goodman et al., 2006). They trigger distinct intracellular cascades divided mainly in $\beta$-catenin-dependent/canonical and $\beta$-catenin-independent/ noncanonical signaling (Clevers and Nusse, 2012). Canonical Wnt signals play fundamental roles during hair follicle development (Huelsken and Birchmeier, 2001; Alonso and Fuchs, 2003). Beyond controlling the initiation of epidermal appendage formation, Wnt signaling contributes to the spatial hair follicle distribution and orientation (Schlake and Sick, 2007).

The present study aimed at analyzing the role of Eviregulated Wnt secretion in the epidermis. To this end, we conditionally deleted the Evi gene in squamous epithelial cells in mice. An abrogation of Evi function resulted in inflamed skin with hyperplasia, impaired barrier function, and differentiation of epidermal keratinocytes as well as vascular hyperplasia. We observed significant dermal infiltration of innate immune cells and T cell recruitment. Interestingly, a significant reduction in dendritic epidermal T cells (DETCs) with high levels of $\gamma \delta \mathrm{T}$ cell receptor was identified in Evi mutant skin. The depletion of DETC started postnatally, suggesting that Wntsecreting keratinocytes play important roles in DETC survival in the murine skin. Moreover, a second $\gamma \delta^{\text {low }} \mathrm{T}$ cell population invaded Evi-LOF epidermis, suggesting that modulation of $\gamma \delta \mathrm{T}$ cell populations contributed to the observed immune cell dysregulation. In addition, Evi-deficient keratinocytes showed increased activation of STAT3. Collectively, the deletion of Evi in keratinocytes created a skin profile resembling chronic cutaneous inflammatory diseases. The data indicates that aberrant control of Wnt secretion leads to severe aberrations during skin homeostasis. We observed that reduced expression of Evi in human psoriatic skin biopsies strengthens the relevance of Wnt signaling in human psoriasis. Therefore, Evi-deficient mice may represent a novel model to study psoriasiform dermatitis-related diseases.

\section{RESULTS \\ Epidermal deletion of Evi leads to growth retardation, early lethality, and irritated skin}

To investigate the role of Wnt secretion during organ development, we generated Evi floxed/floxed mice by homologous recombination deleting exon 3 (Fig. 1,A-C). Global deletion of Evi expression using a pan-deleter $\left(\mathrm{Evi}^{\mathrm{i}}{ }^{\mathrm{l} / \mathrm{fl}}\right.$, Cre-deleter) led to mid-gestational embryonic lethality phenocopying Wnt3adeficient mice, as also reported previously (Fig. 1 D; Fu et al., 2009). Conditional epidermal deletion of Evi was next performed by crossing $\mathrm{Evi}^{\mathrm{f} / \mathrm{fl}}$ mice with K14-Cre mice, which spatially directs Evi deletion into squamous epithelial cells. Expression of the K14 promoter starts during embryonic development (embryonic day 12 [E12]) and remains high in haired as well as hairless skin (Huelsken and Birchmeier, 2001; Huelsken et al., 2001). K14-Cre is expressed in epithelial basal cells, as well as appendages of the skin, and has restricted expression in other epithelial structures like the thymus, esophagus, and forestomach. Evi ${ }^{\mathrm{f} /+}, \mathrm{K} 14-\mathrm{Cre}^{+}$mice appeared phenotypically normal. Evi ${ }^{\text {i/fl }}, \mathrm{K} 14-\mathrm{Cre}^{+}$(Evi-LOF) mice were born at Mendelian frequency and after birth were indistinguishable from their wild-type littermates. As of postnatal day 6, EviLOF pups showed a "red nose" phenotype and retained visibly less dense fur (Fig. 1 E). In addition, Evi-LOF animals showed a growth retardation phenotype and remained significantly smaller until they died within $10 \mathrm{wk}$ (unpublished data).

Evi-LOF mice started losing their hair during the first hair cycle (Fig. 1 F). Also, ears appeared increasingly malformed (Fig. $1 \mathrm{G}$ ), suggesting that epidermal Wnt secretion also affects underlying cartilage formation. In addition, the skin became irritated, flaky, and thin with exposed blood vessels (Fig. $1 \mathrm{H}$ ), and the eyes of Evi-LOF appeared swollen (Fig. 1 I). Based on these visible skin alterations, we performed an extensive histological comparison of wild-type and mutant skin. First, we validated the deletion of epidermal Evi expression by immunohistochemistry (Fig. $1 \mathrm{~J}$ ). Control skin keratinocytes prominently expressed Evi in an irregular pattern. Similarly smooth muscle cells of underlying blood vessels were stained positively; whereas Evi protein was weakly detectable in dermal fibroblast, Evi protein was not detectable in Evi-LOF epidermis, confirming its successful depletion.

Hematoxylin \& eosin (H\&E)-stained sections of Evi-LOF skin revealed dramatic changes in skin structures, which became increasingly severe during the first hair cycle of the skin. Fewer hair follicles developed in Evi-LOF skin, which degenerated to cyst-like structures (Fig. 2 A). Pronounced scale formation was visible on the skin of young pups and persisted throughout the lifetime, indicating impaired keratinocyte differentiation. The epidermis of mutant skin appeared hyperproliferative in contrast to a thin dermis and hypodermis (Fig. 2 A). In normal skin, proliferating cells were detectable in the basal layer of the epidermis and in hair follicle bulbs. The distribution of phospho-H3-positive cells in the skin of Evi-LOF mice showed an increased proportion of proliferating basal cells in Evi-LOF, whereas the number of proliferating cells in the bulb was decreased (Fig. 2, B and C). This data indicates that Evi-LOF epidermis was renewed by rapidly dividing cells in the basal layer and not by proliferating bulge stem cells. Collectively, Evi-LOF skin was displayed by impaired hair follicle formation, dermal degeneration, and enhanced keratinocyte proliferation. 
A wildtype

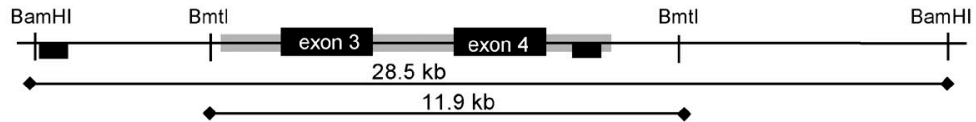

recombined (floxed)

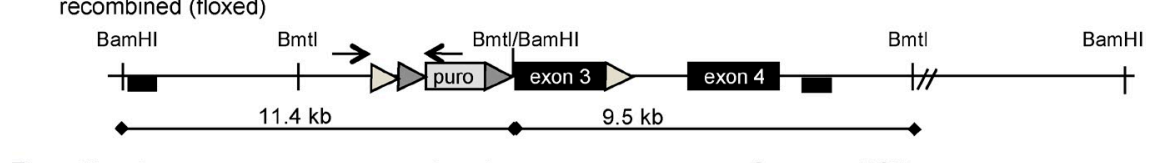

B 5 -probe

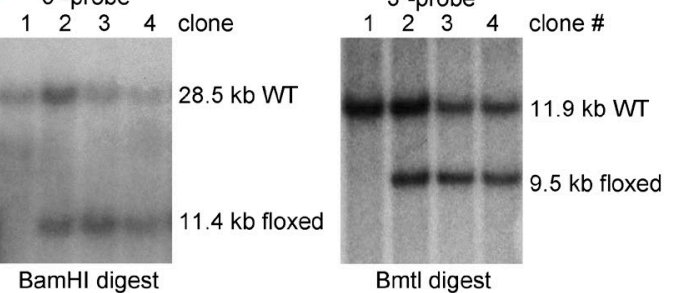

C PCR
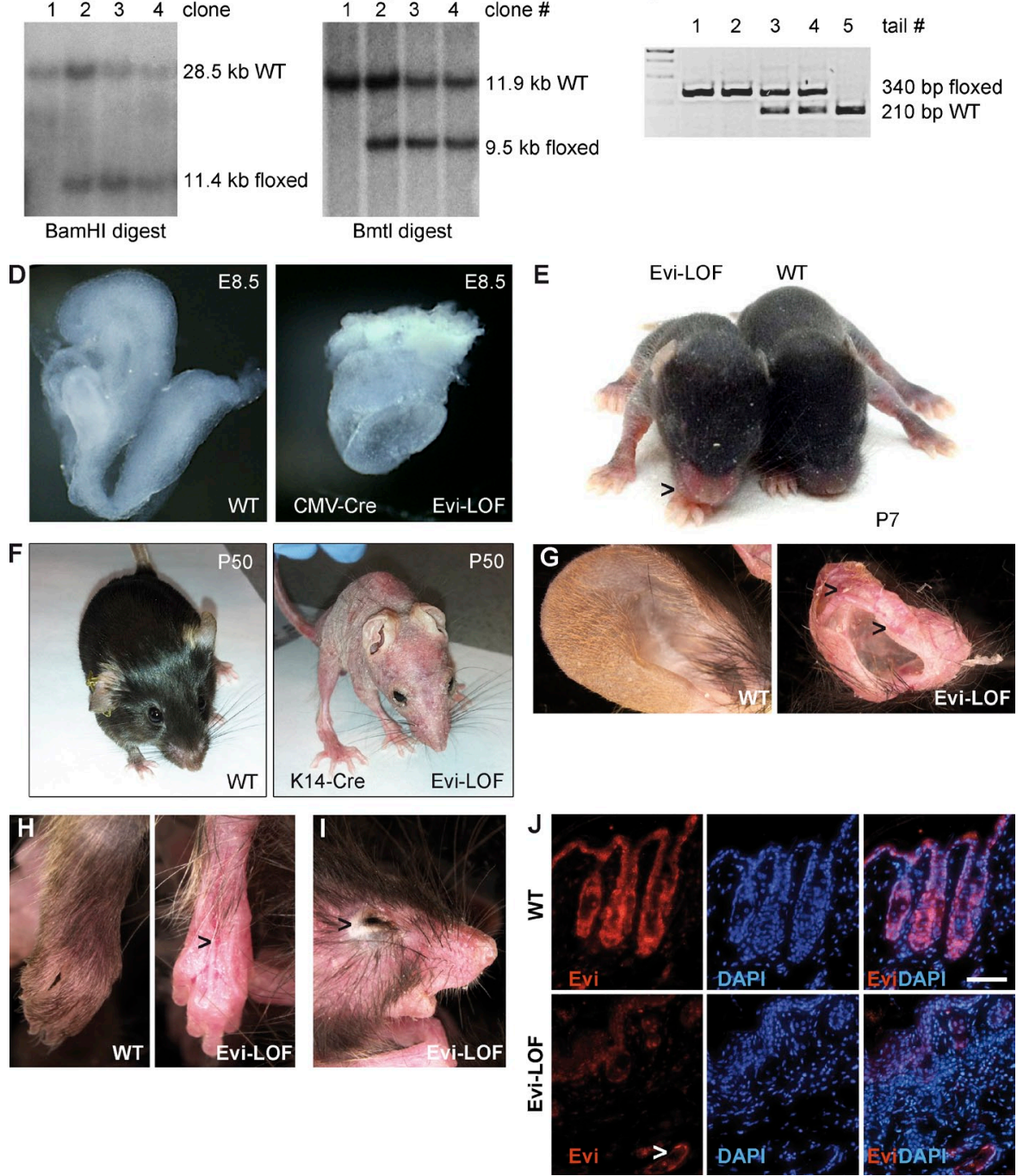

Figure 1. Generation of floxed Evi mice and conditional depletion in squamous epithelium. (A) Targeting strategy for the conditional Evi allele with loxP sites flanking exon3. Thin lines, mouse genomic DNA; gray boxes, sequences included in the targeting construct; triangles, LoxP/FRT sites; black boxes, probes for Southern blot analysis; arrows, PCR primer. (B) Southern blot analysis of genomic ESC DNA digested with BamHI and Bmt1 confirmed homologous recombination with a 5'-primed and $3^{\prime}$-primed probe. (C) PCR analysis of genomic DNA amplified a 340-bp recombined/floxed and a 210-bp wild-type fragment. (D) Crossing of Evif/fl with general Cre deleter generated embryonic lethal Evi knockout mice with defects in gastrulation (embryonic day 8.5 [E8.5]). (E) Evi-LOF and wild-type littermate at age P7 showing the red nose phenotype. (F) Skin phenotyping of Evifl/fil K14-Cre mice (P50 mutant mice [right] and normal littermate [left]). (G) Ears. (H) Legs, exposed blood vessels are marked with arrows. (I) Eye. (J) Immunohistochemistry against Evi in the skin. A representative of three independent experiments is shown. Bars, $200 \mu \mathrm{m}$.

To determine whether other changes in epithelial structures were present in Evi-LOF animals, we probed for the expression of epidermal differentiation markers such as loricrin, Keratin-5 (K5), K8, K14, and K16. Loricrin was expressed in the outer layer of keratinocytes in Evi-LOF mice but not as consistently as in control mice (Fig. 3 A). K5-, K8-, and K14-, as well as basal layer- and hair follicle-expressed marker were similarly distributed in the follicles of wild-type and Evi-LOF 
mice, whereas they were expressed in several layers of the hyperproliferative epidermis in Evi-LOF mice (Fig. 3 A). Interestingly, K16 was enriched in Evi-LOF suprabasal keratinocytes compared with wild-type controls (Fig. 3, A and B). $\mathrm{K} 16$ is a marker for differentiated keratinocytes, which is strongly induced during wound healing (Leigh et al., 1995). Besides providing mechanical integrity, networks of keratin filaments are also involved in cellular functions like apoptosis and stress response (Chamcheu et al., 2011). Therefore, we asked whether additional structural components were differentially regulated and performed expression analysis by RNA-seq of epidermal sheets. We found that a total of 1,298 transcripts were differentially expressed in Evi-LOF epidermis of P21 mice compared with control littermates. Analyses of differing genes revealed the following changes in a set of keratins: K1, K6a, K7, K16, K17, K24, K42, and K79 were found to be up-regulated, whereas the expression of K2, K15, K32, and K77 was down-regulated (Fig. 3 B). Both, K6 and $\mathrm{K} 16$ are involved in wound regeneration, providing strength and resiliency to the skin (Leigh et al., 1995). K1 is involved in hyperkeratosis and contributes to stratum corneum thickening. K17 promotes keratinocyte proliferation and tumor growth by enforcing the immune response in the skin (Depianto et al., 2010). Mutation in the spinous layer keratin K2 has been associated with bullous congenital ichthyosiform erythroderma (Akiyama et al., 2005). K15 expression is down-regulated in hyperproliferative skin, contributing to psoriasis and hypertrophic scars (Waseem et al., 1999). K77 and K32 are involved in hair fiber formation. In summary, the analysis of keratin expression indicates that loss of epidermal Wnt secretion led to differentially regulated expression of several keratin proteins, which are involved in skin regeneration and inflammation.

Moreover, inflammation-associated cytokine expression pattern is altered in Evi-LOF skin, indicating ongoing inflammatory cascades (Fig. $3 \mathrm{C}$ ). Most prominently, the chemokines $\mathrm{Cxcl1}, \mathrm{Ccl} 2, \mathrm{Ccl}$, $\mathrm{Ccl} 20$, and $\mathrm{Ccl} 22$ were up-regulated, Cxcl14 and Cc127a were down-regulated, and expression of the some IL1 family members and IL17f were increased, whereas IL15, IL6f, and IL34 were decreased. Several IL1 family members are involved in cutaneous inflammation. The related IL1 ligands IL1f5, IL1f6, IL1f8, and IL1f9, which were up-regulated in Evi-LOF skin, are linked to cutaneous alterations similar to psoriasis (Blumberg et al., 2007; Onoufriadis et al., 2011). The cytokines IL1f6, IL1f8, and IL1f9 activate pathways leading to NF- $\mathrm{B}$ and MAPK signaling, suggesting a cross talk of these pathways and Wnt signaling in the skin. In summary, this cytokine signature contained genes involved in lymphocyte recruitment (Cxc family members, Ccl family members, and IL17), activation (IL1), proliferation, and survival (IL6, IL7, and IL15) and shows that epidermal loss of Evi correlated with activated immune and inflammatory response.

Inflammation has emerged as a driver of angiogenesis. For this reason, we analyzed the vessel density in the dermis of Evi-LOF skin and wild-type littermates. Quantification of H\&E-stained sections of Evi-LOF revealed significantly more blood filled vessels compared with controls (Fig. 3, D and E).
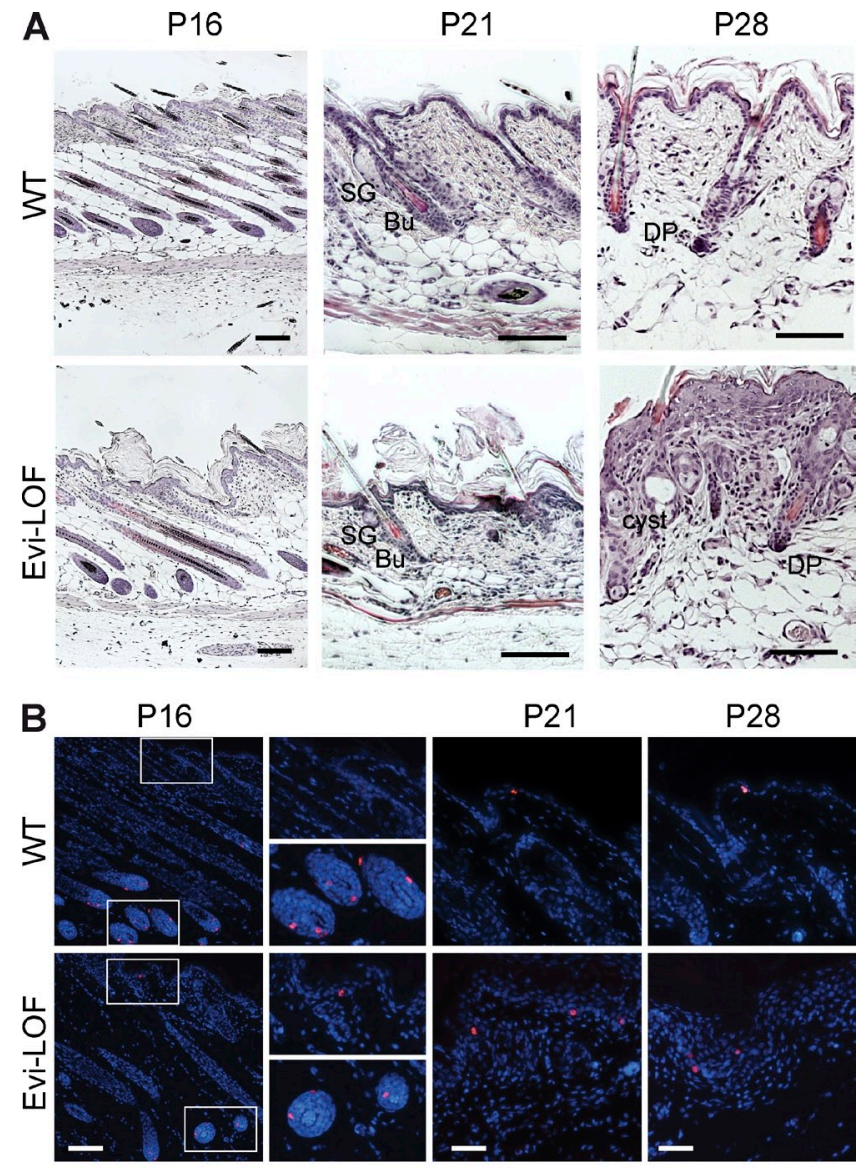

P28
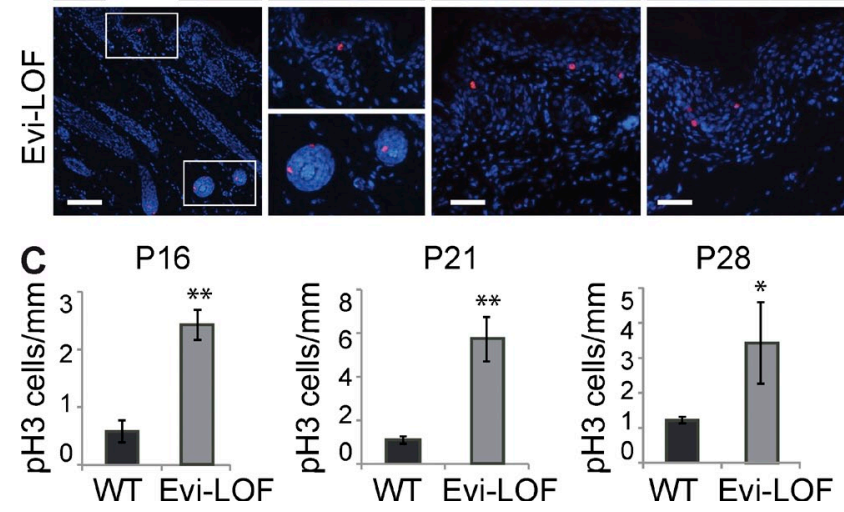

Figure 2. Hyperproliferation of basal cells in Evi-LOF epidermis. (A) H\&E-stained sections of Evi-LOF and control skin at different ages. SG, sebaceous gland; Bu, bulge; DP, dermal papilla. Bars, $200 \mu \mathrm{m}$. (B) PhosphoH3 stainings of skin sections of Evi-LOF and wild-type mice. Bars, $200 \mu \mathrm{m}$. (C) Quantitation of phospho- $\mathrm{H}^{+}-$labeled basal cells/mm. Error bars represent SD. ${ }^{*}, \mathrm{P}<0.05 ;{ }^{* *}, \mathrm{P}<0.001, n=3-4$ per age and group. Results are combined from two independent experiments.

Similar results were obtained with CD31-labeled skin sections (unpublished data), indicating that depletion of Wnt secretion in the epidermis triggered an angiogenic response in Evi-LOF skin.

Ultrastructural analyses revealed multilayering of the epidermis in Evi-LOF skin compared with single-layered wild-type epidermis. In addition, spongiosis was observed in Evi-LOF as a sign of ongoing inflammation and impaired fluid homeostasis, whereas the dermis was thin but otherwise without pathological findings (Fig. 3 F).

The main important function of the skin is to build an effective barrier preventing biological, chemical, and physical 
A
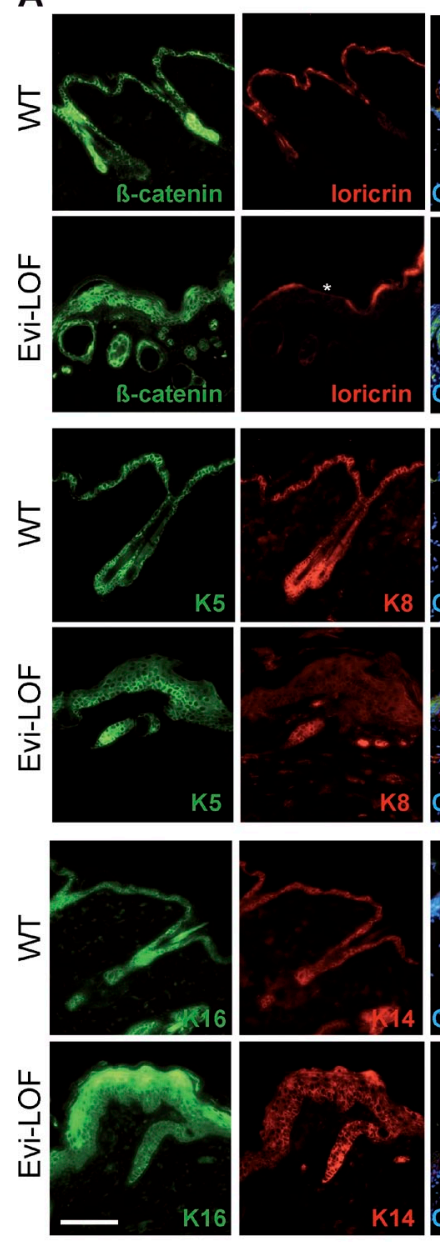
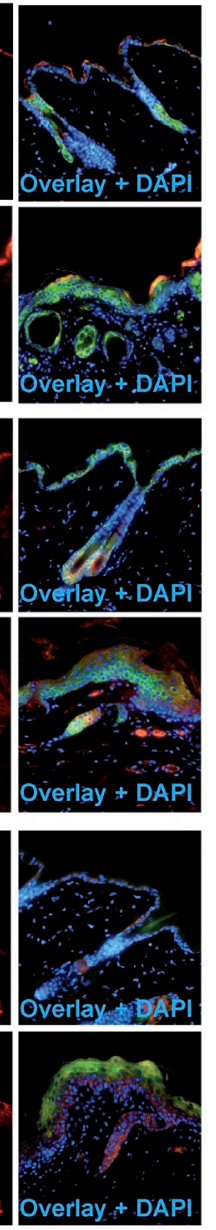

B

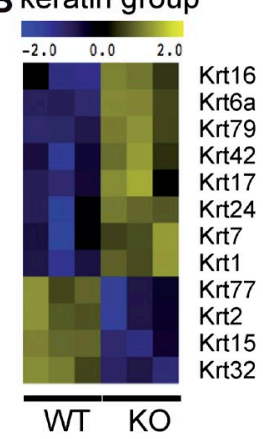

\section{C cytokine group}

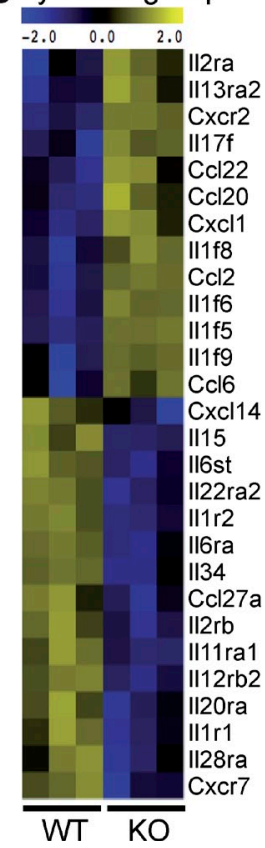

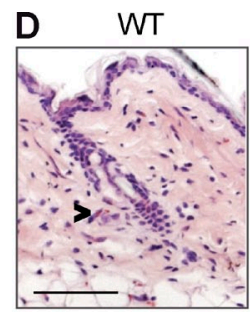
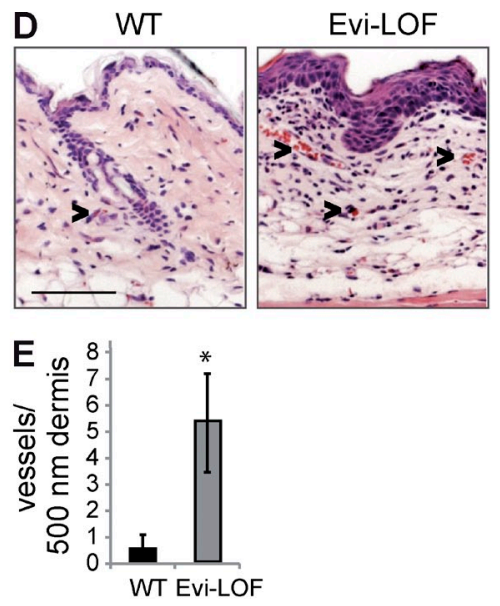

F WT
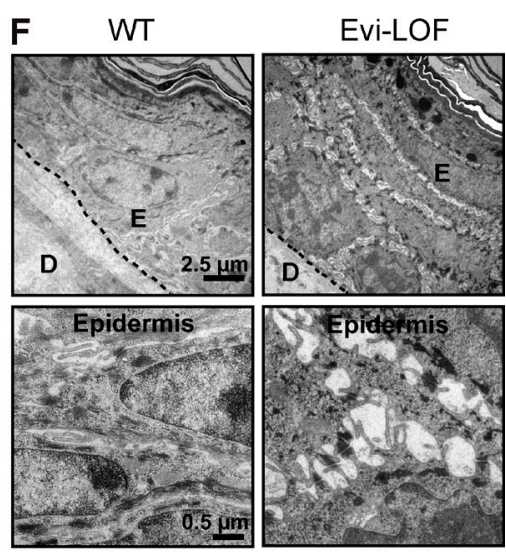

Figure 3. Impaired keratin expression in Evi-LOF indicates ongoing inflammation. (A) Immunohistochemistry against $\beta$-catenin and keratinocyte differentiation marker (loricrin, K5, K8, K16, and K14). Bar, $200 \mu \mathrm{m}$. (B) Expression pattern of differentially expressed keratins in Evi-LOF epidermis based on deep sequencing data. Values represent normalized $\log _{2}$ fold changes $(n=3, P<0.05)$. (C) Heatmap showing cytokines differentially regulated in Evi-LOF epidermis. Values represent normalized $\log _{2}$ fold changes ( $n=3$ per group, $P<0.05$ ). (D) H\&E-stained section of Evi-LOF and control skin. Vessels are marked with arrowheads. Bar, $200 \mu \mathrm{m}$. (E) Comparative analysis of dermal vessel density ( $n=4$ per group, error bars represent SD; $\left.{ }^{*}, \mathrm{P}<0.05\right)$. (F) Ultrastructural characterization of epon-embedded thin sections. D, dermis; E, epidermis ( $n=3$ per group). Results are combined from two (A-C and F) and three (D) independent experiments.

invasion from the outside, as well as retaining solutes from the inside and maintaining thermoregulation (Proksch et al., 2008). Proper epidermal stratification is crucial for the development and homeostasis of epidermal barrier function. Impaired skin permeability function often correlates with inflamed tissue. Therefore, we performed dye-penetration assay with Luciferin yellow and transepidermal water loss (TEWL) analysis to analyze barrier function (Fig. 4, A and B). Both assays revealed a significant alteration in skin barrier function. Neonatal mice showed no skin barrier alterations, whereas older pups (>postnatal day 6 [P6]) developed barrier defects, which lead to dye penetration (Fig. 4 A). Similarly, TEWL analysis revealed dramatic water loss in adult Evi-LOF mice (Fig. 4 B). Therefore, we concluded that the mutant mice embryos formed mature epidermis. However, progressive depletion of Evi function in the epidermis of the pups altered skin penetration. Furthermore, the onset of the barrier alterations was in parallel to first signs of inflammation (red nose phenotype, Fig. 1 E). The data indicates that barrier disruption is time-linked to the onset of skin inflammation and starts rather early in the disease development of Evi-LOF mice. Measurements of surface body temperature of age-matched mice revealed reduced temperature of adult Evi-LOF mice, indicating impaired thermoregulation (Fig. 4 C). The mutant mice also showed a lack of fat tissue sustainment, which suggested that the mice might have balanced the lack of thermoregulation with a hypermetabolic response. Lack of fluid retention, thermoregulation, and sustainment of fat tissue cause stress to the mutant 
A
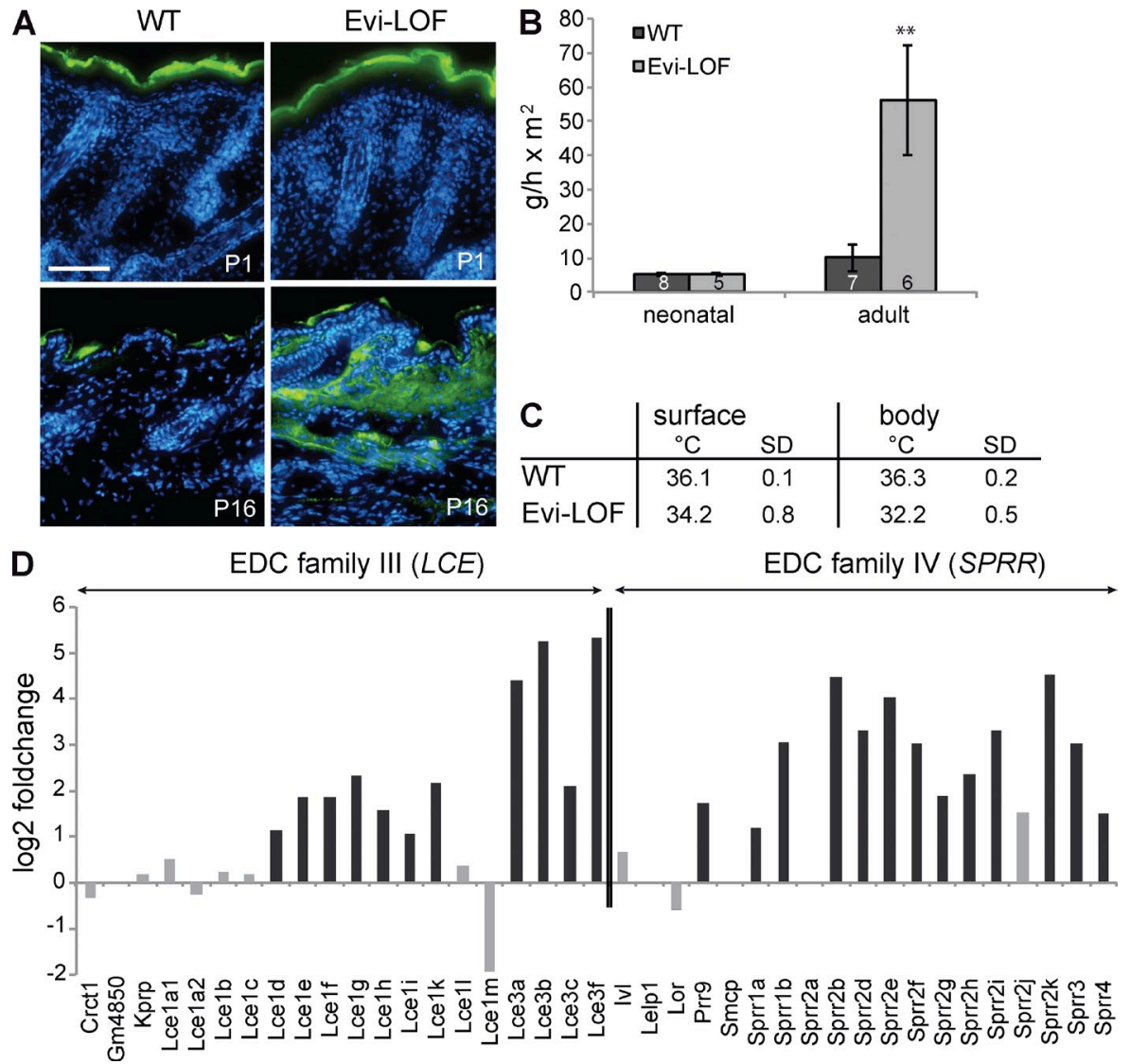

Figure 4. Evi-LOF mice develop skin barrier defects. (A) Lucifer yellow penetration analyzed in newborns and adult mice (bar, $200 \mu m ; n=4$ per group). (B) TEWL analysis of pups and adult mice. Error bars represent SD. (C) Skin surface temperature on shaved skin and body temperature $(n=5$ per group; $\left.{ }^{* *}, P<0.001\right)$. (D) $\log _{2}$ fold changes of EDC gene expression in the epidermis of Evi-LOF skin. Genes with adjusted $p$-values $<0.05$ were labeled in dark gray and genes with adjusted $p$-values $>0.05$ were labeled in light gray. Results are combined from three (A-C) and two (D) independent experiments.

mice and might result in growth retardation and early lethality. In addition expression analysis of epidermal sheets revealed pronounced changes in the transcription of EDC (epidermal differentiation complex) genes (de Guzman Strong et al., 2010; Fig. 4 E). Particularly, most LCE (10 out of 16 genes) and SRPP (12 out of 15 genes) family members are differentially regulated, supporting altered cornification and barrier function in Evi mutant mice. Moreover, LCE3 genes are also involved in barrier repair and psoriatic lesions (Bergboer et al., 2011). Collectively, our results show that the deletion of the Wnt secretory factor Evi in the epidermis led to a complex and severe phenotype including erythema, scaling, altered keratinocyte differentiation, and neoangiogenesis, as well as signs of inflammation and skin barrier perturbations.

\section{Loss of epidermal Wnt secretion leads to chronic inflammatory skin disease}

The observed phenotypic characteristics shared similarities with inflamed skin. We therefore further investigated the skin and performed immunohistochemical analyses of the proinflammatory marker S100A9/Calgranulin B (Nacken et al., 2003). Calgranulin B is highly expressed in neutrophils and is considered to be a potential mediator in psoriasis (Semprini et al., 2002). The dermis of K14-driven Evi-LOF mice was prominently infiltrated by neutrophils starting around age P16 (Fig. 5, A and B). Munro's microabscesses were distributed over the skin of Evi-LOF mice, which we never observed in control littermates (Fig. 5 A). To rule out that neutrophils were recruited to the skin as a result of bacterial infection, mice were orally treated with the broad-spectrum antibiotic ciprofloxacin for $7 \mathrm{~d}$ and analyzed thereafter (Fig. 5 C). No difference in neutrophil infiltration between the littermates with or without antibiotic treatment was observed, indicating that the neutrophil recruitment was not an effect of a bacterial infection. Furthermore, overall pathophysiological analysis of mutant mice revealed no evidence for microbial infection.

Analysis of expression profiling data of mutant and wildtype epidermis showed that the chemokine Cxcl1 $\left(\log _{2}\right.$ fold, 2.02; adjusted [adj.] p-value, 0.0006) and its receptor Cxcr2 $\left(\log _{2}\right.$ fold, 4.4; adj. p-value, $\left.9 \times 10^{-36}\right)$ were differentially regulated (Fig. 3 C). Both genes are involved in neutrophil mobilization and likely contribute to the enhanced neutrophil invasion in Evi-LOF skin. We also examined the infiltration of other innate immune cells like macrophages (CD68) and mast cells (Toluidine) in Evi-LOF skin and controls. Macrophages as well as mast cells were more abundantly detected in 


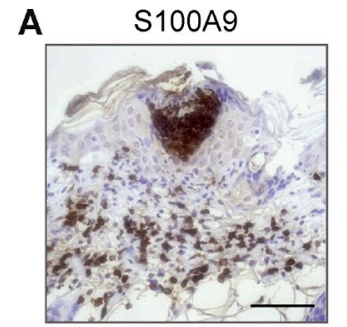

Evi-LOF
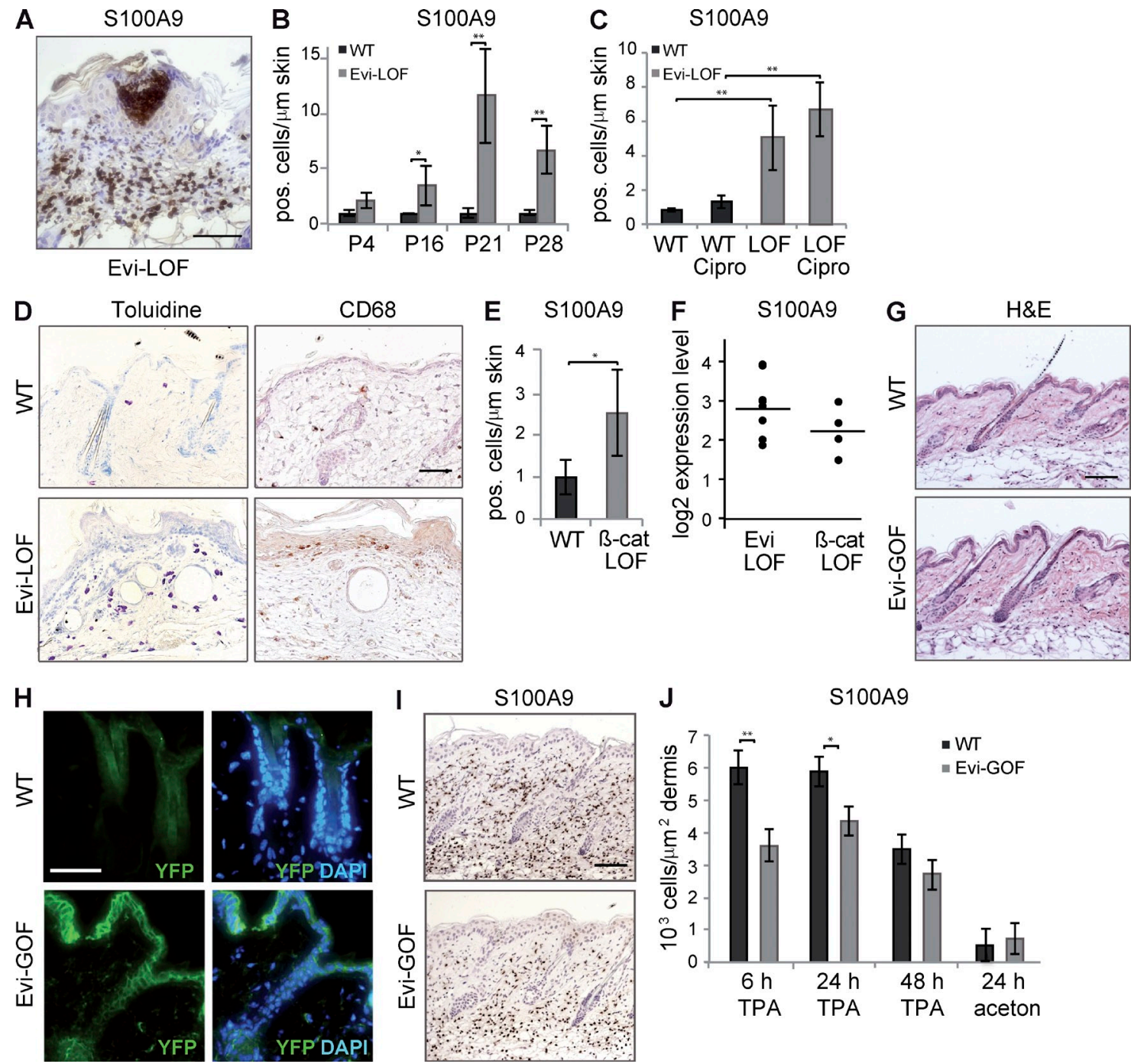

Figure 5. Wnt signaling affects neutrophil recruitment in the skin. (A) Immunohistochemistry against S100A9 in Evi-LOF skin. (B) Quantitation of S100A9-labeled cells in the dermis of Evi-LOF and wild-type littermate skin in differently aged mice ( $n=4$ per age and group). (C) Quantitation of S100A9labeled cells after treatment of Evi-LOF mice and control littermates with or without ciprofloxacin (Cipro; $n=3$ per group). (D) Stainings of mast cell (Toluidine blue) and macrophage (CD68) infiltration ( $n=4$ per group). (E) Quantitation of S100A9-labeled cells in $\beta$-catenin, K14-Cre LOF (P60) mice ( $n=4$ per group). (F) Normalized mRNA expression levels of S100A9 in Evi-LOF and $\beta$-cat-LOF mice. Horizontal bars show mean values ( $n=4$ per group). (G) H\&Estained sections of ROSA26:Evi-YFP (Evi-GOF) knockin and control mice. (H) Expression of Evi-YFP protein in the skin. (I) Immunohistochemistry against S100A9 in skin sections of Evi-GOF and control mice $24 \mathrm{~h}$ after TPA application ( $n=5$ per group and time point). (J) Time-dependent quantitative analysis of dermal S100A9 infiltration after TPA application in Evi-GOF skin compared with control littermates ( $n=5$ per group and time point). Results are combined from three (A-C and E-I) and two (D) independent experiments. Error bars reflect SD (B-E) or SEM (J). ${ }^{*}, P<0.05 ;{ }^{* *}, P<0.001 . B a r s, 200 \mu m$.

Evi-LOF skin, indicating that a spectrum of innate immune cells was involved in the Evi-LOF pathogenesis (Fig. 5 D).

Evi controls the secretion of both canonical and noncanonical Wnt ligands. Therefore, we asked whether Evi-LOF skin inflammation correlated with $\beta$-catenin or $\beta$-cateninindependent Wnt signaling. $\beta$-catenin ${ }^{\mathrm{A} / \mathrm{fl}} \times \mathrm{K} 14$ mutant mice $(\beta$-cat-LOF) mice were viable. Hair follicle formation was impaired in mutants, and $\beta$-cat-LOF mice lost their hair during the first hair cycle, as previously described (Huelsken et al., 2001), and showed a hyperproliferative epidermis; however, they have not been analyzed for an inflammatory phenotype
(Huelsken et al., 2001). Histological quantification of neutrophil recruitment and quantification of S100A9 mRNA expression revealed enhanced infiltration of neutrophils, although to a lesser extent than in Evi-LOF mice (Fig. 5, E and F). These data indicate that canonical Wnt signaling in keratinocytes contributes to skin homeostasis and inflammation. The phenotype of Evi-LOF mutant additionally revealed a reduction of dermal fibroblasts (Chen et al., 2012), which might lead to a more severe inflammatory phenotype compared with $\beta$-cat-LOF.

Next, we asked whether neutrophil recruitment was also affected in Evi gain-of-function animals, assuming that Evi-GOF 

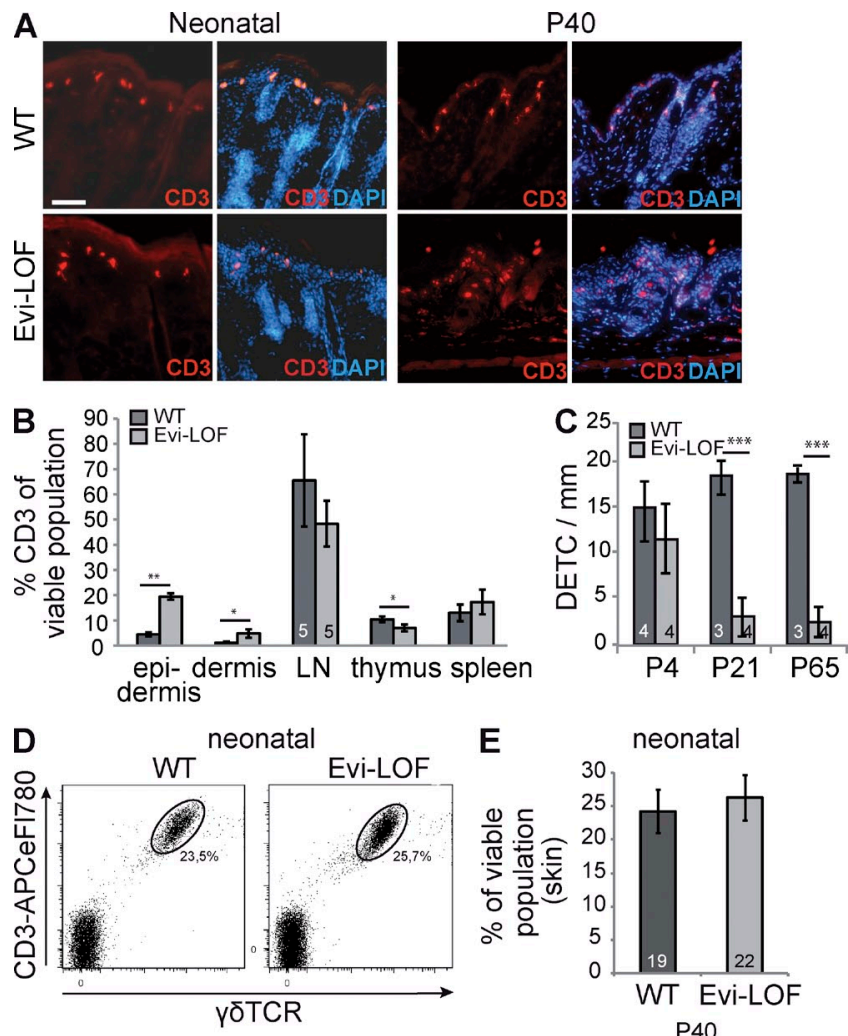

E
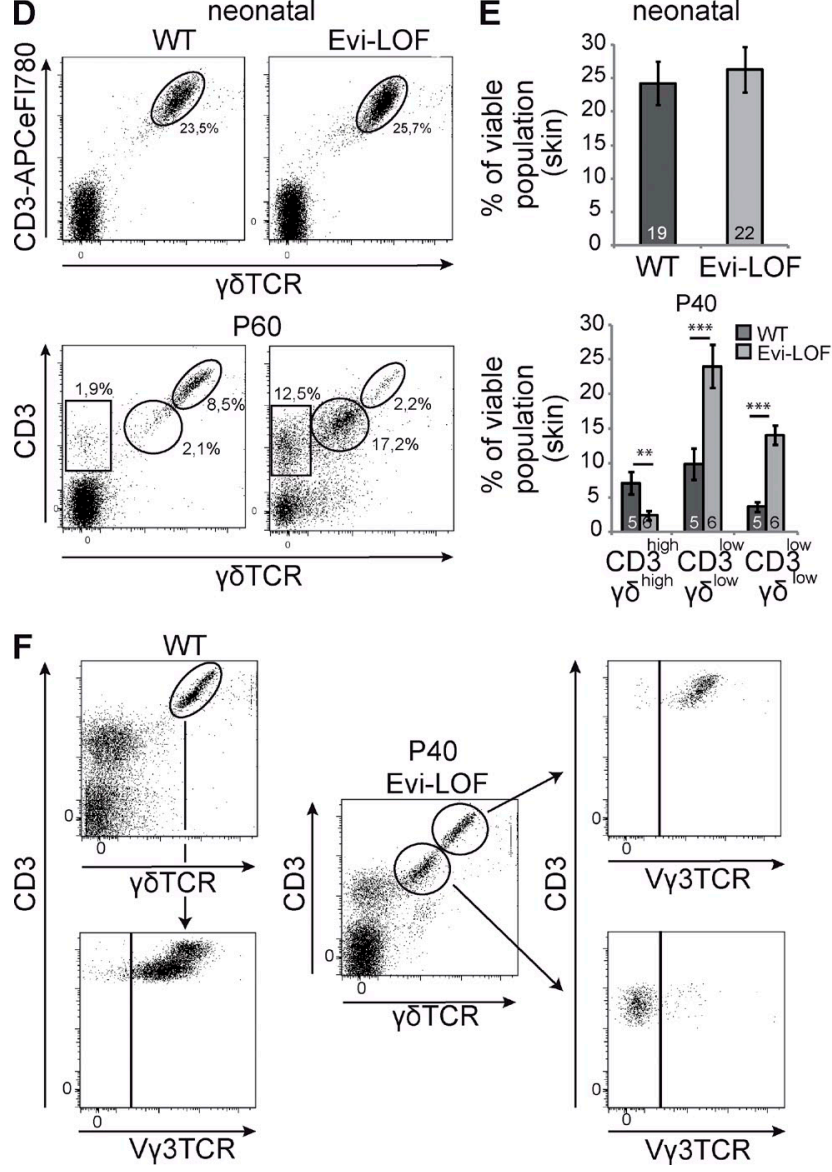

Figure 6. Epidermal depletion of Evi led to loss of DETC and increase in $C D 3^{\text {low }} \boldsymbol{\gamma} \boldsymbol{\delta}^{\text {low }}$ subpopulation in the skin. (A) Expression of $\mathrm{CD} 3$ on frozen skin sections of neonatal mice and paraffin skin section of P40 mice. Bar, $200 \mu \mathrm{m}$. (B) FACS profile of $\mathrm{CD}^{+}$cells in skin and lymphatic tissue ( $n=5$ per group). (C) Quantification of immunohistochemically labeled DETC at different ages ( $n=4$ per group). (D) A representative FACS profile showing the frequency of $\mathrm{CD} 3$ and $\gamma \delta \mathrm{TCR}+\mathrm{T}$ cell subsets of neonatal and P60-old skin. (E) Age-dependent quantitation of $\mathrm{CD}^{+}, \gamma \delta^{+}$cells in the epidermis of Evi-LOF and wild-type littermates. (F) Representative should result in the opposite effect than Evi-LOF. We previously generated ROSA26:Evi-YFP (Evi-GOF) knockin mice (Augustin et al., 2012) and showed that overexpression of EviYFP increased Wnt reporter activity in embryonic stem cell culture. These experiments suggested that the overexpressed Evi protein was functional and secreted Wnt proteins (Augustin et al., 2012). Evi-GOF mice were viable, fertile, and showed no major phenotypic alterations. Overall skin architecture of EviGOF mice was comparable to control skin, indicating that ectopic Evi expression could be tolerated without major pathophysiological consequences (Fig. 5 G). These findings suggested that additional parameters were necessary to overactivate Wnt signaling in vivo. Specific immunofluorescence analysis ofYFP revealed pronounced labeling of keratinocytes, confirming that Evi-YFP protein was ectopically expressed in the skin (Fig. $5 \mathrm{H}$ ). We consequently asked if Evi-GOF showed an effect in a 12-O-tetradecanoylphorbol-13-acetate (TPA) assay of acute regenerative inflammation. TPA induces strong upregulation of proinflammatory signaling molecules and leads to dermal infiltration by immune cells and epidermal hyperplasia. Neutrophils represent the first immune cells recruited after inflammatory induction. We analyzed the dermal infiltration of neutrophils in Evi-GOF and wild-type controls over time. Skin specimens were collected 6, 24, and $48 \mathrm{~h}$ after TPA application. Strong infiltration of neutrophils was observed after 6 and $24 \mathrm{~h}$ of treatment, whereas the infiltration disappeared after $48 \mathrm{~h}$ (Fig. 5, I and J). However, neutrophil infiltration was significantly less in Evi-GOF skin. Acetone-treated Evi-GOF and wild-type mice showed no enhanced immune cell infiltration. The observed reduction of dermal neutrophil infiltration in Evi-GOF mice is consistent with the Evi-LOF phenotype, which was characterized by pronounced neutrophil recruitment. Both lines of experimental approaches support an important role of Evi in skin and immune cell cross talk and suggest a gatekeeper function of Evi in maintaining skin homeostasis.

\section{Epidermal depletion of Evi leads to loss of $\gamma \delta \mathrm{TCR}^{+} \mathrm{T}$ cells in the skin}

Psoriatic skin lesions are usually infiltrated by cell of the innate, as well as adaptive, immune system (Sabat et al., 2007; Nestle et al., 2009). Stainings of neonatal skin with the pan-T cell marker CD3 showed typical labeling of DETC in Evi-LOF and control tissue, whereas additional dermal and epidermal $\mathrm{T}$ cell infiltration was absent (Fig. 6 A). DETCs constitute a $\gamma \delta \mathrm{TCR}^{+} \mathrm{T}$ cell subpopulation, which abundantly expresses $\gamma \delta \mathrm{T}$ cell receptor and specifically localizes to the epidermis of the skin (Girardi, 2004). They reside in the epidermis during the life span of the mouse and are involved in host defense and wound repair (Asarnow et al., 1988).

FACS profiles showing $\mathrm{CD}^{+}$and $\gamma \delta \mathrm{TCR}^{+} \mathrm{T}$ cell subsets (P40) and further analysis regarding $V \gamma 3$ TCR expression. Numbers in columns represent the number of analyzed animals. Results were pooled from three ( $A-C$ and $F)$ and four (D-E) independent experiments. Error bars represent SD (B and $C$ ) or SEM (E). ${ }^{*}, \mathrm{P}<0.05 i^{* *}, \mathrm{P}<0.001 i^{* * *}, \mathrm{P}<0.0001$. 

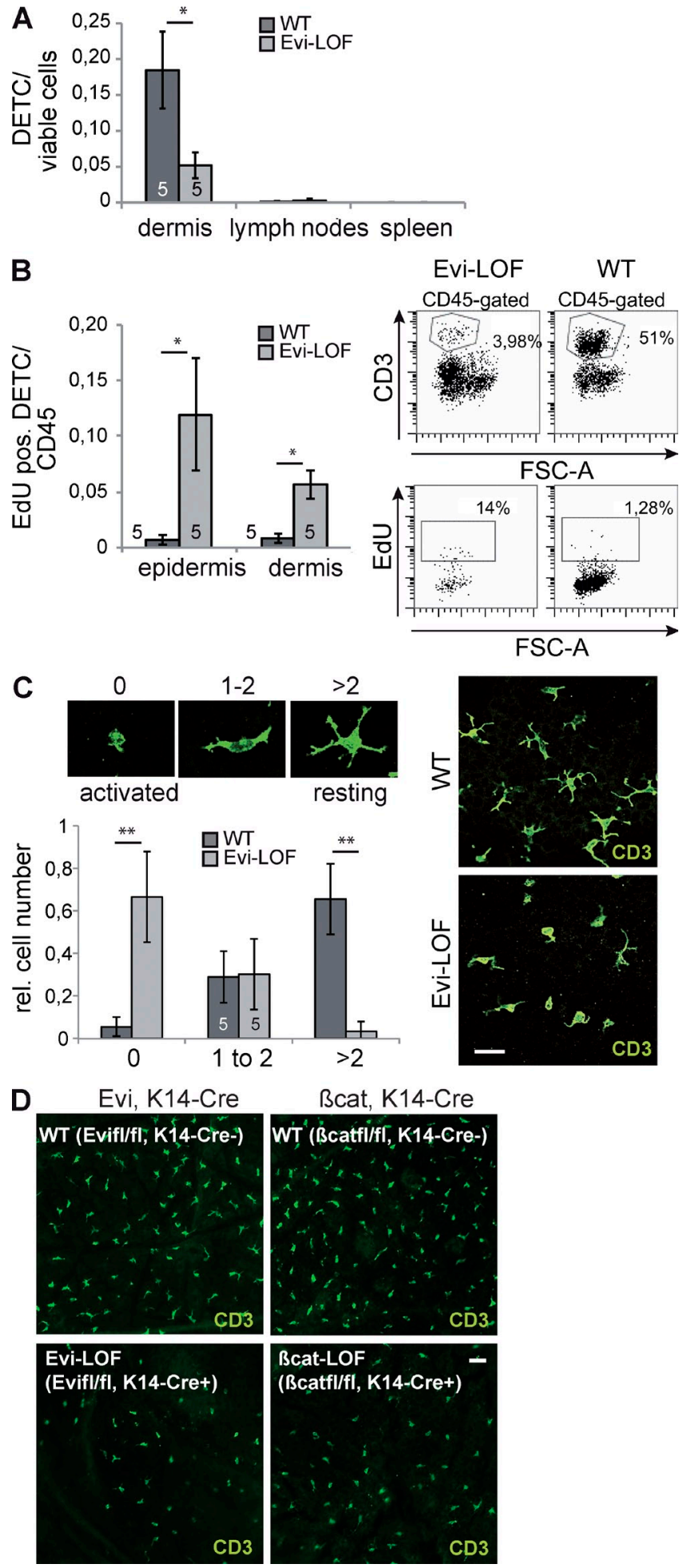

\section{Bcat, K14-Cre}
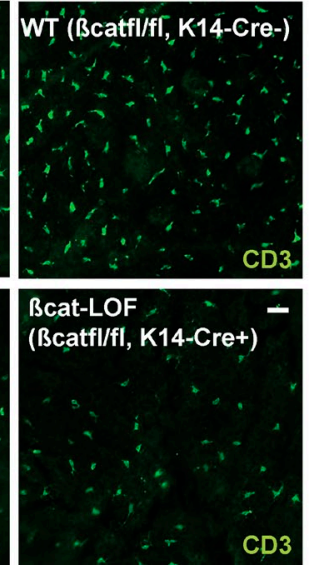

Figure 7. Altered proliferation and activation of DETC in Evi-LOF mice. (A) FACS-based analysis of CD $3^{\text {high }} \gamma \delta^{\text {high }}$ cells in dermis, lymph nodes (LNs), and spleen. (B) EdU incorporation in epidermal and dermal CD $3^{\text {high }}$ cells. FACS plots on the right illustrate the gated populations. (C) Morphological analysis of the activation status of DETC in epidermal ear sheets. Activation status was determined based on number of spines. Bar, $200 \mu \mathrm{m}$. (D) CD3 staining of epidermal ear sheets of Evi, K14-Cre and
CD3 staining of adult Evi-LOF skin revealed few labeled cells resembling DETC morphology and an additional smaller and less intensively stained population, indicating an infiltration of different subpopulations of $\mathrm{CD}^{+}$cells (Fig. $6 \mathrm{~A}$ ). To analyze $\mathrm{T}$ cell distribution in adult Evi-LOF mice and wildtype littermates, we compared the $\mathrm{CD}^{+}$population of the skin and lymphatic tissues (Fig. 6 B). This FACS-based analysis confirmed that Evi-LOF epidermis and dermis had significantly increased $\mathrm{T}$ cell infiltration, whereas the lymph nodes and spleen were unaffected. The results indicate ongoing $\mathrm{T}$ cellbased inflammation in the skin of Evi-LOF mice. In addition, the $\mathrm{CD}^{+}$population of the mutant thymus was decreased, which suggests alterations in $\mathrm{T}$ cell development.

Interestingly, an age-dependent decrease of DETC was observed in Evi-LOF skin, whereas newborn mutant pups showed unchanged DETC populations (Fig. 6, C and D). Thus, it was unlikely that a failure in thymic DETC precursor generation was causally implicated in the absence of DETC in Evi-LOF skin. Instead, the data suggested that the survival of DETC was impaired in Evi-deficient epidermis.

Adult Evi-LOF epidermis contained a second $\gamma \delta \mathrm{T}$ cell population with diminished levels of CD3 and $\gamma \delta \mathrm{T}$ cell receptor levels $\left(C D 3^{\text {low }}\right.$ gdTCR $\left.^{\text {low }}\right)$ compared with DETC $\left(C D 3^{\text {high }}\right.$, $\gamma \delta^{\text {high }}$; Fig. 6, D and E). FACS-based analyses revealed the absence of $\mathrm{V} \gamma 3$ TCR expression (Garman's system) in the CD3 low $\gamma \delta$ low population, indicating that these $\gamma \delta \mathrm{T}$ cells did not reflect features of DETC and probably represented infiltrated dermal or lymphoid $\gamma \delta \mathrm{T}$ cells (Fig. 6 F; Gray et al., 2011; Mabuchi et al., 2011).

To rule out loss of DETC as a result of DETC emigration out of the epidermis, we prepared cell suspensions of the dermis, lymph nodes, and spleen and quantified DETC by FACS profiling (Fig. $7 \mathrm{~A}$ ). DETC population is decreased in the dermis and not changed in lymphoid tissues, indicating that DETC did not migrate into adjacent tissue or lymphoid organs. The data supports our concept that survival of DETC is impaired in Wnt-deficient epidermis.

Next, we asked whether the DETC loss is a result of impaired proliferation and activation. Therefore, we labeled proliferating cells with (29S)-29-Deoxy-29-fluoro-5-ethynyluridine (EdU) and quantified EdU-containing DETC by FACS. DETC isolated from epidermal, as well as dermal cell suspensions of mutant skin, revealed increased EdU incorporation, indicating enhanced cell proliferation (Fig. 7 B). In addition we analyzed the activation status of the DETC in Evi-LOF epidermal ear sheets and compared it to control mice (Fig. 7 C). As shown in Fig. $7 \mathrm{C}$, the majority of the DETC in control ears form dendritic spines $(>2)$ typical for resting DETC, and only $5 \%$ are activated. However, Evi mutants obtained $\sim 65 \%$ activated DETC and $<5 \%$ resting DETC, indicating that DETC

$\beta$-cat, K14-Cre in K14- $\beta$-cat-LOF mice. Bar, $400 \mu m$ ( $n=4$ per group). Numbers in columns represent the number of analyzed animals. Results were pooled from three ( $\mathrm{A}$ and $\mathrm{C}$ ) and two $(\mathrm{B})$ independent experiments. Error bars represent SD. ${ }^{*}, \mathrm{P}<0.05{ }^{* *}, \mathrm{P}<0.001$. 

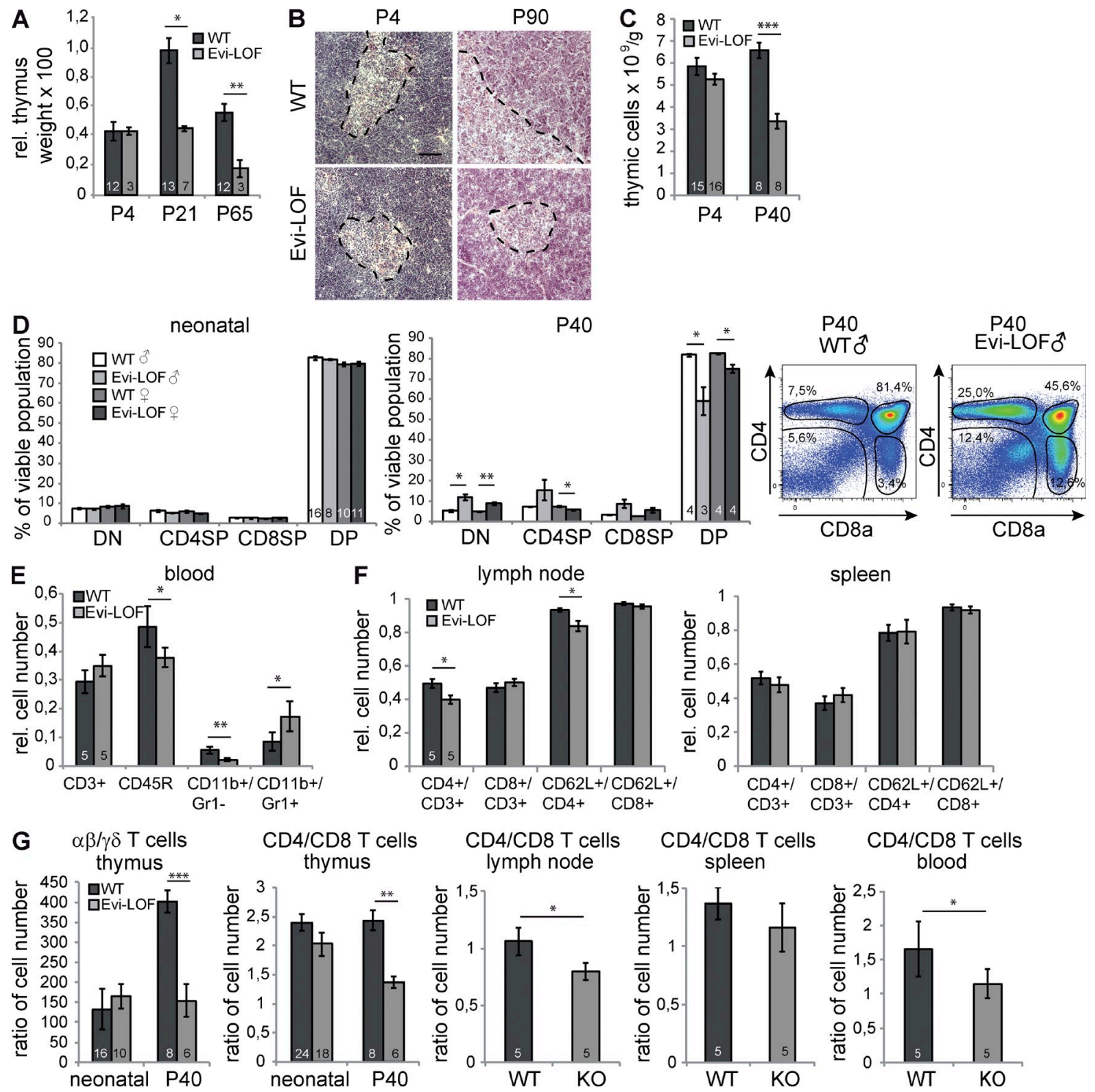

CD4/CD8 T cells thymus

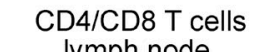

CD4/CD8 T cells

CD4/CD8 T cells
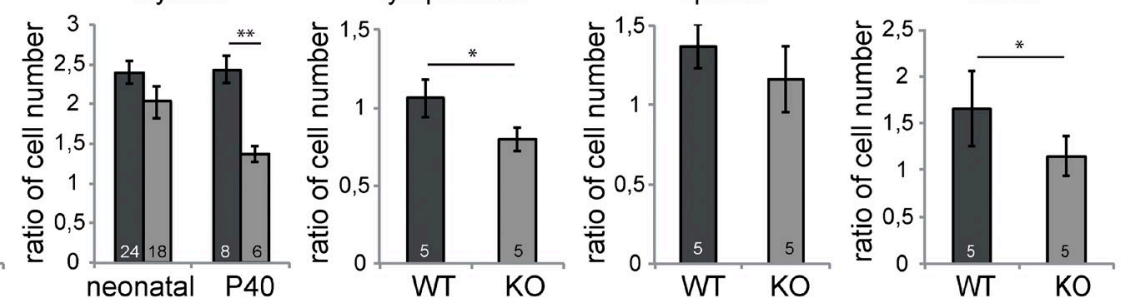

H Foxn1-Cre

K14-Cre

K14-Cre

$\beta$-catenin $\mathrm{fl} / \mathrm{fl}$

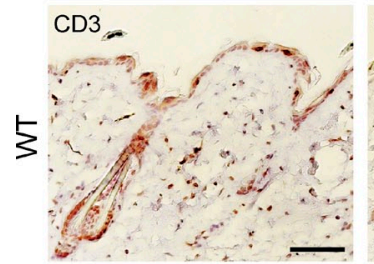

$\mathrm{CD} 3$

CD3
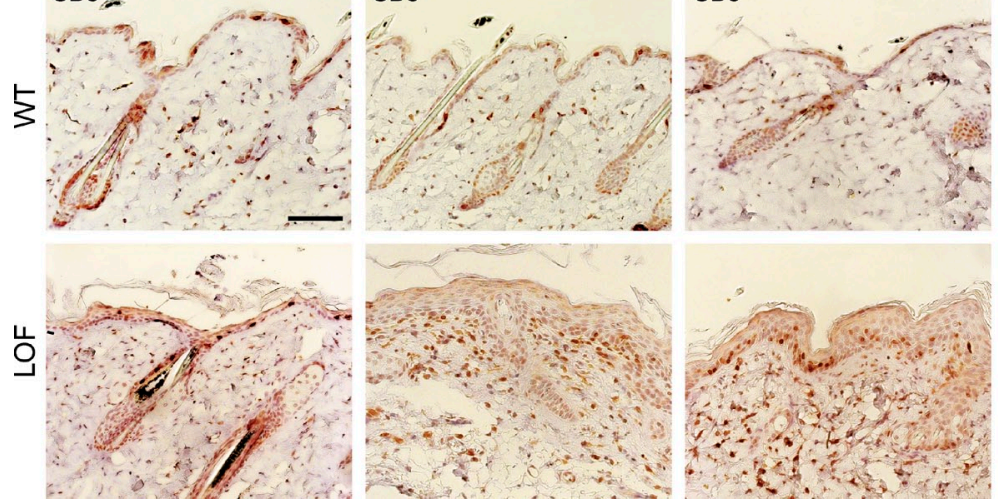

Figure 8. Thymic and thymocyte development in Evi-LOF mice and immunophenotyping of blood and lymphoid tissue. (A) Thymus weight normalized to body weight in mice of different ages (P4, P21, and P65). (B) H\&E-stained sections of Evi-LOF and control thymi at different ages. Dashed lines indicate transition between cortex and medulla. Bar, $500 \mu \mathrm{m}$. (C) Total thymus cellularity in mice of different age. (D) Frequencies of CD4-CD8double-negative (DN), CD4+ single-positive (CD4SP), CD8 ${ }^{+}$single-positive (CD8SP), and CD4+CD8 ${ }^{+}$double-positive (DP) thymocytes of P4 and P40 mice 
in Evi-LOF skin had sensitized epidermal stress, got activated, and started to proliferate. These results reflect the typical phenotype of stimulated DETC. Loss of DETC is therefore not a result of absence of DETC activation and proliferation but rather results from lack of sustainment signals. Similarly, $\beta$-catenin-K14-LOF mice showed reduced DETC population, supporting a role of Wnt signaling in DETC maintenance (Fig. 7 D).

Next, we asked whether $\gamma \delta \mathrm{T}$ cell ligands are changed in Evi-LOF skin. Skint1 is expressed in epithelial cells of the thymus and the skin. It is involved in the selection of the DETC compartment in the thymus (Boyden et al., 2008; Barbee et al., 2011). However, its function in the skin is still unclear. Skint1 was up-regulated in Evi-LOF epidermis ( $\log _{2}$ fold, 1.02; adj. p-value, 0.0001), suggesting that Skint1 expressed by keratinocytes might contribute to the $\gamma \delta \mathrm{T}$ cell distribution in $\mathrm{mu}-$ tant epidermis. Moreover, previous reports had shown that IL15 promotes $\gamma \delta \mathrm{TCR}^{+} \mathrm{T}$ cell sustainment (Edelbaum et al., 1995). Correspondingly, a significant reduction of IL15 expression was observed in Evi-LOF skin compared with wildtype control $\left(\log _{2}\right.$ fold, -1.85 reduction; adj. p-value, $2.2 \times$ $\left.10^{-5}\right)$. This data indicates that Wnt signaling is involved in IL15 expression in the skin, which plays an essential role for DETC survival.

The K14 promoter is also expressed by thymic epithelial cells (TECs) of the inner medullar region (McLelland et al., 2011). We consequently asked if the restricted Evi depletion in TEC had an effect on the structure and $\mathrm{T}$ cell composition of the thymus. The relative weight of the thymus in Evi-LOF pups (P4) was similar compared with control mice. However, the weight of the thymus was significantly reduced in older mutant animals (P21 and P65), indicating that the thymi regressed due to enhanced atrophy (Fig. 8 A). H\&E stainings of $\mathrm{P} 4$ and $\mathrm{P} 28$ thymic sections revealed no differences in the overall thymic architecture between Evi-LOF and wild-type mice (Fig. 8 B). Cortex and medulla structures were clearly separated with comparable sizes in younger mice. Thymi of older mice (P90) had discernible differences in thymic architecture leading to a reduction of medulla in mutant mice (Fig. 8 B). Total thymus cellularity of P4 Evi-LOF thymi was unaltered (Fig. $8 \mathrm{C}$ ). However, thymus cellularity in atrophic thymi of older mice (P40) was $\sim 50 \%$ reduced (Fig. 8 C). Analyses of cell surface markers demonstrated that the thymocyte set distribution $\left(\mathrm{CD}^{-} \mathrm{CD}^{-}\right.$double-negative $[\mathrm{DN}], \mathrm{CD}^{+}$singlepositive, $\mathrm{CD}^{+}$single-positive, and $\mathrm{CD}^{+}{ }^{+} \mathrm{CD}^{+}$double-positive $[\mathrm{DP}]$ cells) of $\mathrm{P} 4$ Evi-LOF thymi were indistinguishable from control littermates (Fig. 8 D). Thymocyte populations of P40 Evi-LOF thymi were significantly altered, with an increase in $\mathrm{DN}$ and loss of DP thymocytes, and reflect similar thymocyte distribution to that in endotoxin-induced thymic atrophy (Fig. 8, D and E; Billard et al., 2011).

In addition, altered distribution of leukocyte populations in the blood as well as increased population of activated CD4 cells in the lymph node of the mutants suggested disturbed homeostasis and activation of cell-mediated immunity (Fig. 8, E and F). Reduced B cell compartment and increased granulocyte compartment in the bone marrow had been reported after inflammation. Our data suggests that the blood phenotype mirrors the reciprocal production of $\mathrm{B}$ cells and granulocytes in the bone marrow under inflammation (Cain et al., 2009). Altered ratios of thymic $\alpha \beta \mathrm{T}$ cells versus $\gamma \delta \mathrm{T}$ cells, as well as between CD4 and CD8 $\mathrm{T}$ cells, revealed significantly reduced ratios in adult mice, suggesting shifts in T cell maturation (Fig. $8 \mathrm{G}$ ). The data demonstrates that the thymic alteration in adult Evi-LOF mice also had an immune modulatory effect in the periphery. Collectively, Evi-LOF mice develop atrophy of lymphoid tissues and impaired immune homeostasis, suggesting dysfunctions of cellmediated immunity and ongoing inflammation.

Further analyses of Evi ${ }^{\mathrm{f} / \mathrm{fl}} \times$ FoxN1-Cre $($ FoxN1-Evi-LOF) offspring were performed to clarify the initial cause of skin inflammation. FoxN1-Cre mice are commonly used as a Cre driver for thymic epithelium. The Cre expression is directed to TEC precursors as well as to mature TEC. Moreover, the FoxN1 promoter is active in some epithelial cells of the skin (Mecklenburg et al., 2001; Schlake, 2001; Gordon et al., 2007). FoxN1-Evi-LOF mice were viable and had slightly less dense hair than wild-type controls but showed no prominent signs of inflammation. DETCs were normally distributed and T cell infiltration was absent in mutant mice (Fig. $8 \mathrm{H}$ ). Consequently, $\mathrm{Evi}^{\mathrm{H} / \mathrm{fl}}$, FoxN1-Cre mice did not develop inflamed skin, which supports the concept that epidermal Evi depletion, but not aberrant $\mathrm{T}$ cell development, triggered the inflammatory cascades.

Collectively, the data indicate that depletion of epidermal Wnt secretion leads to an inflammatory phenotype, which enforced T cell recruitment but inhibited survival of DETC. This phenotype did not correlate with severe thymic or thymocyte developmental defects. Rather, the dramatic reduction in thymic $\mathrm{T}$ cell development and loss of DP thymocytes in older Evi-LOF mice (P40) reflected characteristic changes after thymic atrophy in response to stress (Billard et al., 2011). Similarly, depletion of DKK1 in TEC had no effect on frequency of thymocyte subsets (Osada et al., 2010).

derived from either females or males. Representative FACS plots were shown on the right. (E) Whole blood from adults mice was analyzed by FACS with the indicated antigens for T cells (CD3), B cells (CD45R), monocytes (CD11 b+ Gr1-), and granulocytes (CD $\left.11 b^{+}, \mathrm{Gr} 1^{+}\right)$. (F) FACS-based analysis of naive (CD62 L expressing) $\mathrm{CD}^{+}$and $\mathrm{CD} 8^{+} \mathrm{T}$ cells in secondary lymphatic tissue. Evi-LOF tissue had less naive CD4+ cells in the lymph node, indicating activation of cell-mediated immunity probably based on chronic skin inflammation and stress. (G) $\alpha \beta$ and $\gamma \delta$ T cells as well as CD4+ and CD8 $8^{+}$populations of the indicated tissues were analyzed via FACS profiling. Diagrams illustrate ratios of the populations and indicate impaired T cell homeostasis. Results were pooled from three $(A, C$ and $D)$ from two $(B$ and $E-G)$ independent experiments. ${ }^{*}, P<0.05 ;{ }^{* *}, P<0.001 ;{ }^{* * *}, P<0.0001$. Error bars represent $S E M(A-D)$ or SD (E-G). (H) Skin sections of FoxN1-Evi-LOF (P90), K14-Evi-LOF (P40), and K14- $\beta$ cat-LOF (P60) were stained with CD3. Only K14-Evi-LOF and $\beta$-cat-LOF mice revealed enhanced T cell recruitment. FoxN1-Evi-LOF skin had well developed hair follicles and no hyperproliferative epidermis. Bar, $250 \mu m(n=4$ per group). Representative pictures of two independent experiments were shown. 

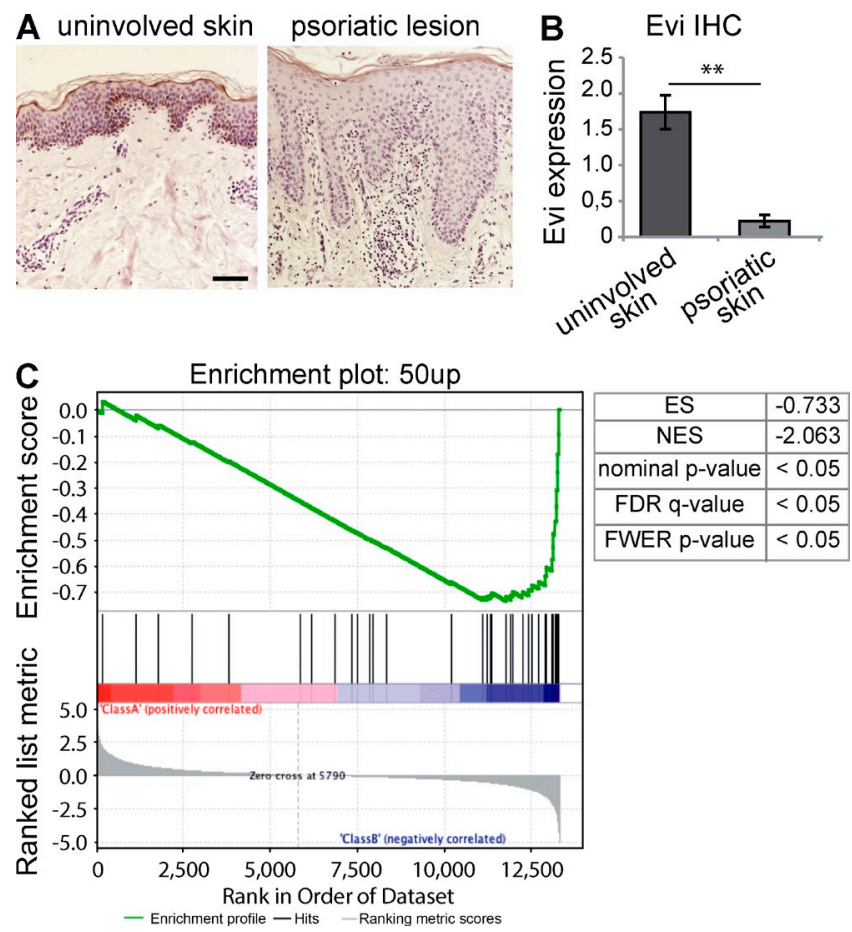

Figure 9. Evi was down-regulated in human psoriasis. (A) A representative analysis out of 12 psoriasis samples and control tissue stained against Evi. Bar, $100 \mu \mathrm{m}$. (B) Quantitation of Evi expression in skin biopsies based on immunohistochemistry (Error bars represent $S D, n=12$; $\left.{ }^{*}, P<0.001\right)$. Results were pooled from two independent experiments. (C) Enrichment plot showing a significant correlation between the 50 most up-regulated genes in human psoriasis compared with the expression profile of Evi-LOF epidermal sheets.

\section{Evi is down-regulated in human psoriatic skin}

Next, we asked whether Evi itself was differentially regulated in human psoriasis. We analyzed the expression of Evi by immunohistochemical stainings of unaffected and affected areas of biopsy samples from psoriatic patients $(n=12$; Fig. 9 A). Evi was abundantly expressed in healthy skin with higher levels in the basal layer. In contrast, Evi expression was prominently down-regulated in psoriatic lesions (Fig. 9 B), suggesting a causative involvement of Evi in the development of the disease. Correspondingly, reanalysis of psoriatic and normal human skin expression studies (Yano et al., 2008) revealed a significant reduction of Evi mRNA expression in psoriatic skin lesions $\left(\log _{2}\right.$ fold change -0.8 , adj. p-value $\left.7.63 \times 10^{-9}\right)$. In addition, gene set enrichment analysis comparing psoriatic skin profile (Swindell et al., 2011) with Evi-LOF expression data showed a significant correlation with genes up-regulated in psoriasis (FWER p-value of down-regulated genes 0.057, not depicted; Fig. 9 C).

\section{Evi-deficient keratinocytes induce inflammation via STAT3 activation}

STAT3 signaling is involved in skin wound healing. Aberrant wound healing response has been shown for psoriatic epithelium (McKenzie and Sabin, 2003). Consequently, consistent up-regulation of STAT3 signaling in keratinocytes contributes to skin diseases like psoriasis (Sano et al., 2005). IL17f reflects a proinflammatory cytokine up-regulated in Evi-LOF skin (Fig. $3 \mathrm{C}$ ) and is known to activate STAT3 signaling. A previous study also revealed that IL17a, which is highly homologous to IL17f, activates via STAT3 the expression of the psoriasisassociated K17 (Swindell et al., 2011). To analyze whether STAT3 signaling is induced in Evi-LOF skin, we examined the levels of phosphorylated STAT3. Evi-LOF epidermal sections showed a prominent nuclear staining of activated STAT3 compared with control tissues (Fig. 10 A). Correspondingly, protein levels of phosphorylated STAT3 were significantly increased (Fig. 10 B). Analysis of RNA-seq expression data of epidermal sheets revealed several STAT3 signaling-related genes, which were differentially expressed in Evi-LOF skin. Several cytokines (Ccl22, Ccl20, Cxcl1, Ccl2, IL1f5, and IL15) involved in immune cell mobilization were significantly changed in Evi-LOF epidermis (Fig. 10 C). Histochemical stainings of $\mathrm{K} 14-\beta$-catenin mice revealed enhanced nuclear STAT3 in K14- $\beta$-catenin-LOF skin, indicating that canonical Wnt signaling contributes to activation of STAT3 (Fig. 10 D). The data suggest that Wnt secretion functions upstream of STAT3 in an autocrine manner.

\section{DISCUSSION}

Ablation of $\beta$-catenin causes a lack of placode formation during embryogenesis and loss of hair in the first hair cycle, suggesting that $\beta$-catenin-dependent Wnt signaling controls differentiation of stem cells into follicular or epidermal lineages (Huelsken et al., 2001; Akiyama et al., 2005). Recent studies showed that ectodermal Wnt secretion is required for hair follicle initiation and proliferation of dermal fibroblast (Chen et al., 2012; Myung et al., 2013). Ectopic expression of the secreted canonical Wnt signal inhibitor DKK1 in epidermal cells displayed developmental skin defects (Andl et al., 2002). K14-driven loss of $A p c$ resulted in delayed and aberrant hair follicles morphogenesis as well as thymus degeneration (Kuraguchi et al., 2006). However, no Wnt-related mouse model has so far addressed the effect of Wnt signaling in skin homeostasis with respect to inflammation. In the present study, the Evi gene was conditionally depleted in squamous epithelial cells. Abrogation of Evi function in these mice resulted in inflamed skin with hyperplasia, impaired differentiation of epidermal keratinocytes and barrier function, vascular hyperplasia, and infiltration of immune cells. Significant infiltration of leukocytes like neutrophils was observed. Neutrophils are effector cells of the innate immune response and play important roles during tissue damage in acute disease as well as chronic diseases. In psoriasis, prominent infiltration and microabscess formation by neutrophils is a characteristic feature (Schön et al., 2000). Expression of chemoattractants together with the corresponding receptors by neutrophils is required to recruit neutrophils to the site of inflammation (Sadik et al., 2011). The chemokine Cxcl1 and its receptor CxcR1 play important roles in neutrophil mobilization. Both genes were significantly up-regulated in Evi-LOF skin. In addition, Cxcl1 is a target gene of STAT3, which was 

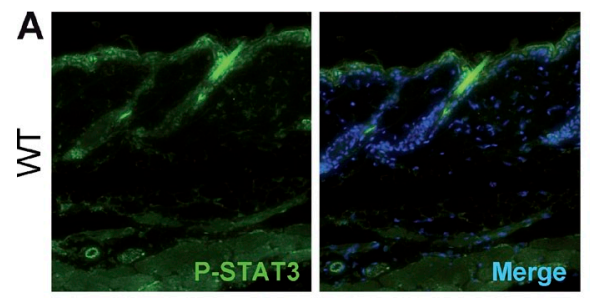

B
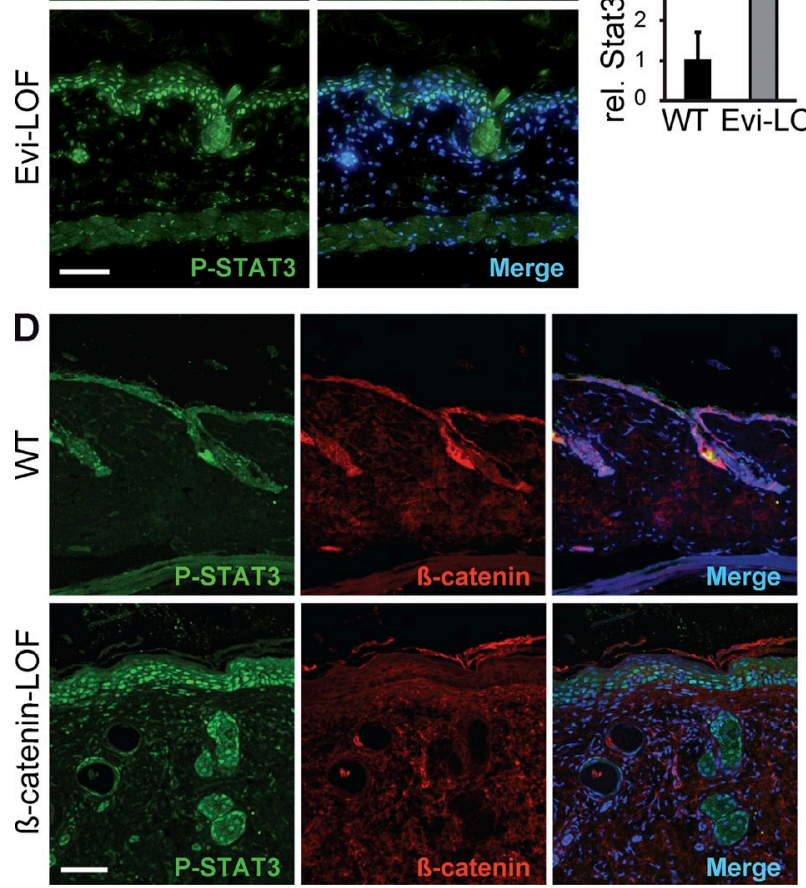

also activated in Evi-LOF skin. These data support our previous findings of Evi function during glioma tumorigenesis (Augustin et al., 2012), which had indicated that STAT3 signaling functions downstream of Evi. Moreover, STAT3 has previously been shown to play a major role in skin wound healing and is also up-regulated in human psoriatic lesions. As such K5-STAT3 transgenic mice develop psoriasis-like phenotype (Sano et al., 2005).

The existence of impaired skin permeability function is widely accepted in inflammatory skin diseases like atopic dermatitis and psoriasis (Proksch et al., 2008). Whether the barrier disruption is followed by inflammation or whether inflammation leads to permeability alterations is not clear.A definite conclusion about the initial contribution of altered skin barrier function or inflammation in our mouse model is also difficult because the defect appears to arise together with first signs of skin inflammation. However, skin barrier alteration in Evi-LOF mice precedes the onset of the adaptive immune system activation because infiltration of T cells is significantly observed in juvenile mice and not pups. Cutaneous barrier defects have not been linked to the altered Wnt signaling pathway before. Therefore, we believe that this Wnt-associated phenotype is an interesting finding and will open new questions for future studies.

The model described in this study establishes that epidermal alterations in Wnt secretion induce cutaneous inflammation. Current concepts of inflammatory skin disorders postulate an
C

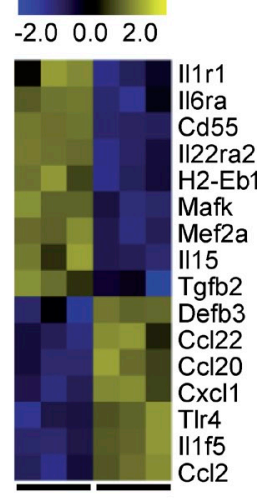

WT Evi-LOF
Figure 10. STAT3 signaling is activated in EviLOF skin. (A) Immunohistochemistry against P-STAT3. Bar, $200 \mu m$ ( $n=4$ per group). (B) Quantitative Western blot analysis of P-STAT3 expression in the epidermis. ( $n=8$ per group; Error bars represent SD; ${ }^{*}, \mathrm{P}<$ 0.05). (C) Heatmap showing STAT3 signaling-related genes, which are differentially regulated in the epidermis of Evi-LOF and control mice. Values represent normalized $\log _{2}$ fold changes $(n=3$ per group, $\mathrm{P}<$ 0.01). (D) Immunohistochemistry against P-STAT3 in $\beta$-catenin-LOF epidermis. Bar, $200 \mu \mathrm{m}$ ( $n=4$ per group). Results were pooled form three (A and B) and two (C and D) experiments. important functional role of T cells in the pathogenesis of the disease (Lowes et al., 2007). Consistent with these reports, $\mathrm{T}$ cell recruitment was observed in Evi-LOF skin. Unlike the vast majority of mature $\alpha \beta \mathrm{T}$ lymphocytes, which reside in secondary lymphoid organs and are recruited upon immune response, subsets of $\gamma \delta \mathrm{T}$ cells preferentially reside in epithelia such as the epidermis, gut, lung, or the genitourinary tract. FACS profiling of mutant adult epithelium revealed two $\gamma \delta$ $\mathrm{TCR}^{+}$populations, a CD $3^{\text {high }} \gamma \delta^{\text {high }}$ and a second subpopulation with $\mathrm{CD} 3^{\text {low }} \gamma \delta^{\text {low }}$ cells. Previous studies based on human psoriatic patient material had indicated that the $\gamma \delta$ T cell population is enhanced in psoriatic plaques (Seung et al., 2007). Similarly, the appearance of CD $3^{\text {low }} \gamma \delta^{\text {low }}$ cells in IL23-induced psoriatic dermatitis suggests a common mechanism between this psoriasis mouse model and Evi-LOF skin (Mabuchi et al., 2011). Functional impairment at an epithelial interface can be attributed to up-regulation of local $\gamma \delta$ TCR subsets. Nevertheless, the observed depletion of DETC (CD $\left.3^{\text {high }} \gamma \delta^{\text {high }}\right)$, which started postnatally, suggests that Wnt-secreting keratinocytes are essential for DETC survival in the murine skin. DETCs play a major role in the maintenance of the epidermal barrier and confine inflammatory infiltration of tissue provoked by conventional $\alpha \beta$ T cells (Hayday and Tigelaar, 2003; Bonneville et al., 2010; Macleod and Havran, 2011). It has been shown that DETC-deficient NOD mice develop spontaneous dermatitis (Girardi, 2004), suggesting that the absence of 
DETC in Evi-deficient mice contributed to the observed immune cell dysregulation. IL15 is preferentially expressed in nonlymphoid tissues and promotes growth of DETC (Edelbaum et al., 1995). Moreover, IL15-LOF mice were deficient in epidermal DETC cells, indicating that IL15 is essential for the survival of DETC in the skin (De Creus et al., 2002). The down-regulation of IL15 in Evi-LOF skin suggests a role of IL15 as limiting survival factor of DETC in Evi mutants. Interestingly, other $\gamma \delta \mathrm{T}$ cell subpopulations, except DETC, are independent of IL15 (Sumaria et al., 2011).

The results of this study also reveal that partial Evi deficiency in TECs did not contribute to aberrant $\mathrm{T}$ cell development. Furthermore, the phenotypic analysis of skin samples from Evi ${ }^{\text {Al/ }}$ FoxN1-Cre (FoxN1-Evi-LOF) mice was consistent with these results. FoxN1 expression is restricted to epithelial cells of the thymus from earliest stage of thymus organogenesis and subsets of keratinocytes in the epidermis and in hair follicles (Mecklenburg et al., 2001; Schlake, 2001; Gordon et al., 2007). FoxN1-Evi-LOF mice lead to a mosaic depletion of Evi in the epidermis, which caused minor hair loss in the mutant skin. In contrast, FoxN1-Cre induced a more penetrant excision of the Evi gene in thymus epithelium compared with K14-Cre and, therefore, a more efficient thymic epithelial knockout. Nevertheless FoxN1-Evi-LOF mice did not develop skin inflammation comparable to that of K14Evi-LOF, supporting a model whereby Evi depletion in keratinocytes is responsible for the initiation of the psoriasiform dermatitis-like phenotype.

Much progress has been made in the past in defining molecular lesions, which are associated with predisposition to chronic inflammatory skin diseases and consequently also in the development of novel therapeutic modalities. Considering the heterogeneity of the patient phenotypes, the aim of future treatment will be to reduce the immune response and associated angiogenesis as well as hyperplasia. This study shows that epidermal depletion of the Wnt secretion factor Evi unexpectedly triggered skin barrier defect, immune infiltration, and the growth of cutaneous blood vessels and keratinocytes. Taking into account that chronic inflammatory skin diseases are complex multifactorial disorders, which beyond patientspecific heterogeneity also have many inflammatory genes in common, Evi-deficient mice reflect similarities to human cutaneous skin inflammation and suggest that our mutant mice may represent a novel model for psoriasiform dermatitisrelated diseases. Future studies into the development of novel therapeutics should consider the contribution of Wnt signaling on disease-associated immune modulation.

\section{MATERIALS AND METHODS}

Mice. The vector for the targeting of the Evi locus contained loxP sites flanking exon 3 of the Evi gene. The loxP sites enclosed a FRT-flanked pgkneo selection cassette, which was excised in vivo using a flippase-expressing mouse line. The targeting construct was introduced in C57BL/6 embryonic stem cells, which were injected into blastocysts to generate chimeric mice. Three independently targeted ES cell clones gave rise to mutant mice. Mice were genotyped by PCR and Southern blot analysis. The following primers were used to identify wild-type and recombinant alleles by PCR: forward, 5' -AAGGAAACGAGATTGAGATGAGG-3'; reverse, 5'-GTTTATTTTTCCTCTTACCACTCTG-3'. Generation of the mice was performed by Taconic Artemis.

For Southern blot analysis, genomic DNA was digested with BamHI and Bmtl and probed with fragments, which were amplified with the following primers: probe1, forward 5'-TAGGAGAATATGAGTTGAAAAGAGG-3', reverse 5'-AGGTGTGCCCTTTGAGAAAAGATC-3'; and probe 2, forward 5'-AATTAGCCTGTCATCTAGATTGTG-3', and reverse 5' -ACATTAAAGGCACAGATCTACAAGG-3'. ROSA26:Evi-YFP (Evi-GOF) were previously described (Augustin et al., 2012). In brief, Evi cDNA was C-terminally tagged with YFP and inserted into the ROSA26 locus by homologous recombination. A loxP-flanked $\beta$-geo cassette was integrated preceding the Evi sequence.

Floxed Evi $\left(\mathrm{Evi}^{\mathrm{f} / \mathrm{fl}}\right)$ mice were crossed to Cre-deleter mice (Schwenk et al., 1995) or keratinocyte-specific keratin14 promoter (K14-Cre) to delete exon 3 and obtain Evi-LOF mice. Floxed ROSA26 Evi-YFP mice were crossed with Cre deleter to induce Evi-YFP expression. Floxed $\beta$-catenin $\left(\beta-\mathrm{cat}^{\mathrm{f} / \mathrm{fl}}\right)$ mice (Huelsken et al., 2001) were crossed with K14-Cre. Evi ${ }^{\mathrm{H} / \mathrm{fl}}$ were crossed with FoxN1-Cre (Soza-Ried et al., 2008). Evi ${ }^{\mathrm{A} / \mathrm{Al}}$, ROSA26: Evi-YFP, Cre-driver mice were on a C57BL/6 background ( $>10$ backcrosses), and $\beta$-catenin ${ }^{\mathrm{f} / \mathrm{fl}}$ mice were on a mixed background. Mice were housed in individually ventilated cages under specific pathogen-free conditions. Animals had free access to food and water and lived in a 12-h light-dark cycle and were used at indicated ages. In each experiment mutant and control littermates were used. At least three litters were tested. Pap tests were performed to identify bacteria species on the skin of the analyzed mouse colonies. Some mice had been tested positive for Staphylococcus xylosus, which is a nonpathogenic commensal on the skin of mice. In parallel, the effectiveness of the antibiotic Ciprofloxacin had been positively tested against the Staphylococcus present in the mouse colony and we had no evidence for an infection with resistant strains. Therefore, mice were orally treated with Ciprofloxacin to exclude bacterial infection as a reason for inflammation.

TPA-induced hyperplasia. 7-8-wk-old female wild-type and Evi-GOF mice were used for TPA experiments. Mice were shaved $3 \mathrm{~d}$ before treatment. TPA $(100 \mu \mathrm{l}, 10 \mathrm{nM})$ was dissolved in acetone and applied on the dorsal skin. Skin specimens were collected after 6,24 , and $48 \mathrm{~h}$ and processed for paraffin embedding. The experiment was performed with five mice per genotype and treatment group. Animal welfare and experimental procedures were performed in accordance to German animal protection law and were approved by the Regierungspräsidium Karlsruhe, Germany (AZ 230/11).

Western blotting. Epidermal sheets were isolated as previously described (Jensen et al., 2010). Skin specimens were incubated in dispase II overnight. The epidermis was separated mechanically from the dermis. Epidermal or total skin preparations were dissolved in lysis buffer containing $8 \mathrm{M}$ urea in PBS. Lysates were incubated on ice for $10 \mathrm{~min}$ and centrifuged at $12,000 \mathrm{~g}$ for $20 \mathrm{~min}$. The supernatants were collected and protein concentrations were determined by BCA method. $30 \mu \mathrm{g}$ of proteins were separated on $4-12 \%$ NuPage gradient gels and transferred to PVDF membranes. Membranes were blocked and incubated overnight at $4^{\circ} \mathrm{C}$ for $1 \mathrm{~h}$ at room temperature with the following antibodies: P-STAT3 (New England BioLabs) and STAT3 (New England BioLabs). Blots were then incubated with corresponding horseradish peroxidase-conjugated secondary antibodies (Sigma-Aldrich). Blots were also probed with a mouse monoclonal antibody against $\beta$-actin (Sigma-Aldrich).

Immunohistochemistry of tissue sections and epidermal sheets. Immunohistochemical studies were performed on paraffin-embedded and fresh frozen section as previously described (Augustin et al., 2012). In brief, antigen retrieval of paraffin sections was performed by microwaving the sections for $10 \mathrm{~min}$ in $10 \mathrm{mM}$ citrate buffer, $\mathrm{pH}$ 6.0, or Tris-EDTA, pH 9. Fresh frozen sections were fixed with $4 \%$ paraformaldehyde or methanol. The sections were incubated overnight at $4^{\circ} \mathrm{C}$ with the following primary 
antibodies: Evi (C1, DKFZ), CD3 (Abcam), $\gamma \delta \mathrm{T}$ cells (BD), CD31 (BD), CD68 (Santa Cruz Biotechnology, Inc.), S100A9 (Santa Cruz Biotechnology, Inc.), $\beta$-catenin (BD), loricrin (Abcam), K14 (Abcam), K16 (Acris), Phospho-H3 (New England BioLabs), and P-STAT3 (Abcam). All stainings were performed with $\mathrm{AB}$ complex enhancement. Nuclei were counterstained using Hoechst dye or Hematoxylin. For staining of epidermal sheets, ears were briefly washed in $70 \%$ ethanol.The ventral and dorsal sides of each ear were separated with forceps and incubated with epidermis down on $3.8 \%$ ammonium thiocyanate for $15 \mathrm{~min}$ at $37^{\circ} \mathrm{C}$. Epidermal sheets were peeled off, put on a slide, and immunostained after fixation with $4 \%$ paraformaldehyde. Negative control experiments included omission of the primary antibody. Tissue analyses were performed with biopsies derived from at least three samples per genotype from independent litters. Stained sections were visualized by bright field or immunofluorescence microscopy (Axiovert $200 \mathrm{M}$ with Visitron software; Carl Zeiss) at indicated magnifications. Image processing was performed with Photoshop CS4 software (Adobe). Quantification of labeled cells was done with the help of ImageJ (National Institutes of Health. Psoriatic and uninvolved skin samples from patients were obtained from the Department of Dermatology and Venereology, University of Cologne. All samples were analyzed in an anonymized manner as approved by the local institutional ethics boards (AZ 188-8).

Ultrastructural analysis. Tissue pieces of $1 \times 1 \mathrm{~mm}$ were fixed in $4 \%$ paraformaldehyde overnight and embedded in epon. Thin sections of three different specimens per genotype were analyzed with an electron microscope (EM 900; Carl Zeiss).

Skin permeability barrier assays. Lucifer yellow dye assays were performed with neonatal, P6, and adult mice. The mice were euthanized, gently shaved, briefly washed with $70 \%$ ethanol, and immersed for $1 \mathrm{~h}$ at $37^{\circ} \mathrm{C}$ in $1 \mathrm{mM}$ Lucifer yellow dye (Sigma-Aldrich) dissolved in PBS. Back skin strips were collected and frozen. Tissues were sectioned $(10 \mu \mathrm{m})$, postfixed for $0.5 \mathrm{~h}$ in $4 \%$ paraformaldehyde, and counterstained using Hoechst dye. Stained sections were visualized by immunofluorescence microscopy (Axiovert 200M with Visitron software) at 20× magnification. Detection of TEWL was performed on shaved back skin with a Tewameter TW300 (Courage Khazaka Electronics).

Tissue preparation and cell isolation for flow cytometry. Thymi, spleens, and lymph nodes of mice of different age were surgically removed, cut into small pieces, and teased to a single-cell suspension through a $70-\mu \mathrm{m}$ cell strainer. Remaining cells were flushed out by rinsing with ice-cold FACS buffer ( $5 \%$ fetal bovine serum in PBS). Lymphocytes were centrifuged at $300 \mathrm{~g}$ for $5 \mathrm{~min}$ and resuspended in $0.5-2 \mathrm{ml} \mathrm{FACS}$ buffer. Cells were counted using a hemocytometer.

Back skin was rinsed with $70 \%$ alcohol, washed with PBS, and floated with the dermal side facing down in Dispase II solution $(5 \mathrm{mg} / \mathrm{ml}$ Dispase II sterile filtrate (Roche) in T cell medium $(10 \mathrm{mM}$ Hepes buffer, $1 \mathrm{mM}$ sodium private, $10 \% \mathrm{FCS}$, and $55 \mu \mathrm{M} \beta$-mercaptoethanol in RPMI) at $37^{\circ} \mathrm{C}$ for $3 \mathrm{~h}$. The dermis was mechanically separated from the epidermis on the next day. Both were cut into small pieces. The epidermis was incubated in $0.25 \%$ trypsin/EDTA in DMEM (Invitrogen) for $15 \mathrm{~min}$. Dermis was digested with $0.2 \mathrm{mg} / \mathrm{ml}$ Collagenase I, $0.25 \%$ trypsin/EDTA in DMEM for $1 \mathrm{~h}$ at $37^{\circ} \mathrm{C}$. Cells were isolated by shaking vigorously until the solution became opaque. The cell suspension was filtered through a $70-\mu \mathrm{m}$ cell strainer and $\mathrm{T}$ cell medium was added. The cells were centrifuged at $350 \mathrm{~g}$ for $5 \mathrm{~min}$ and resuspended in FACS buffer.

Cell suspensions were added to FACS buffer containing diluted antibody, incubated for $30 \mathrm{~min}$ at $4^{\circ} \mathrm{C}$, washed, and resuspended in FACS buffer. For blood cell phenotyping, $2 \mu \mathrm{l}$ of whole blood was stained in $100 \mu \mathrm{l}$ of total volume and analyzed. Immunophenotype data were acquired on a FACS Canto II (BD) and analyzed with FlowJo software (Tree Star; DKFZ Flow Cytometry Core Facility, Heidelberg, Germany).

Cell surface stainings were performed with anti-mouse directly conjugated monoclonal antibodies: anti-CD3 APC-eFluor780 (eBioscience), anti-CD45
APC (BD), anti-TCR $-\beta$ chain FITC (BD), anti- $\gamma \delta-$ TCR PE (BD), antiCD45R PCB (Invitrogen), anti-CD11b PE (Invitrogen), anti-Gr1 (BD), anti-CD4 FITC (BioLegend), anti-CD8a PE-Cy5 (BD), anti-CD44 Alexa Fluor 647 (BioLegend), anti-CD25 PE (BioLegend), anti-CD62L FITC (eBioscience), and anti-V $\gamma 3$ TCR FITC (BD).

EdU labeling in vivo. Mice were injected i.p. with EdU $(20 \mu \mathrm{g} / \mathrm{g}$ mouse) on 5 consecutive days. Epidermal and dermal cell suspensions were prepared at day 6 after initial EdU administration. Cells were stained with CD3 antibody as described in previous section. EdU-labeled cells were visualized by Click-iT EdU Pacific Blue Flow Cytometry Assay kit (Life Technologies).

Real-time transcription (RT)-PCR analysis. Total RNA was extracted from epidermal sheets of mouse back skin using RNeasy extraction kit (QIAGEN) according to the manufacturer's instructions. Reverse transcription and quantitative PCR was performed with 25 ng cDNA and LightCycler 480 Probes Master as described (Roche). Relative mRNA expression was calculated as a fold change versus control. Primers were as follows: S100A9: probe \#31, forward 5'-CACCCTGAGCAAGAAGGAAT- ${ }^{\prime}$, and reverse 5'-TGTCATTTATGAGGGCTTCATTT-3'.

Expression profiling of Evi silencing experiments. RNA was extracted from epidermal sheets of three wild-type and Evi-LOF mice. The poly(A) ${ }^{+}$ fraction was isolated from each of the six samples with the Dynabeads mRNA Purification kit (Invitrogen). For each sample, a library for sequencing with a SOLiD4 sequencer was prepared. In brief, random primers with a hexamer adapter sequence were annealed to the $3^{\prime}$ end of the mRNA and the first DNA strand synthesized. After RNA digestion, the DNA was purified using Agencourt RNAClean XP Beads. Random primers were annealed to the DNA for second strand synthesis. Agencourt Ampure XP Bead selection was used to purify and size select the double-stranded DNA. The library was amplified and barcoded.

Deep sequencing on a SOLiD4 system generated 50-base-long nucleotide sequences, referred to as "reads." These were mapped using the whole transcriptome analysis pipeline (Bioscope). This algorithm incorporates exonboundary information to map reads to a genome. For this analysis, the Mus musculus genome (NCBIM37) and associated exon boundary information was obtained from Ensembl (release 67). Bioscope adopts a seed-and-extend approach to map reads, and here a 25-base seed region was used, allowing two mismatches in the seed region. To ensure high accuracy, reads that mapped to multiple locations were discarded and only those reads that aligned with a high quality score $(>20)$ were considered. The number of reads mapping to gene loci was quantified using Python package HTSeq (v0.4.7). Expression profiling data has been deposited in ArrayExpress (accession no. E.MTAB-1613).

Statistical analysis. Unless otherwise indicated, data are expressed as mean \pm $\mathrm{SD}$. Statistical significance was calculated by a two-tailed Student's $t$ test with unequal variance. A p-value of $<0.05$ was considered statistically significant and marked by asterisks. Two asterisks represent $\mathrm{p}$-values of $<0.01$. Differential expression in RNASeq data were estimated using Bioconductor package DESeq (v1.7), with $n=3$. A p-value of $<0.05$ was considered significant.

We are grateful to Tabea Arnsberger and Jeanette Friemann for excellent technical assistance. We thank Jeffery Zielich for stainings and evaluation of the TPA-treated skin section, Svenja Leible and Thilo Miersch for RNAseq experiments of epidermal RNA, Karin Müller-Decker for TPA treatment of the mice, the DKFZ FACS core facility for providing access to FACS instruments, Taconic Artemis for transgenesis, and Richard Jennemann for introduction in TEWL analysis.

This work was supported by a Marie-Curie Excellence Grant "Cellular Signaling" from the European Commission, the DFG, and the Z2 project of SFB829.

The authors declare no competing financial interests.

Submitted: 18 August 2012

Accepted: 15 July 2013 


\section{REFERENCES}

Akiyama, M., Y. Tsuji-Abe, M. Yanagihara, K. Nakajima, H. Kodama, M. Yaosaka, M. Abe, D. Sawamura, and H. Shimizu. 2005. Ichthyosis bullosa of Siemens: its correct diagnosis facilitated by molecular genetic testing. Br. J. Dermatol. 152:1353-1356. http://dx.doi.org/10.1111/ j.1365-2133.2005.06598.x

Alonso, L., and E. Fuchs. 2003. Stem cells of the skin epithelium. Proc. Natl. Acad. Sci. USA. 100:11830-11835. http://dx.doi.org/10.1073/pnas .1734203100

Andl, T., S.T. Reddy, T. Gaddapara, and S.E. Millar. 2002. WNT signals are required for the initiation of hair follicle development. Dev. Cell. 2:643-653. http://dx.doi.org/10.1016/S1534-5807(02)00167-3

Asarnow, D.M., W.A. Kuziel, M. Bonyhadi, R.E. Tigelaar, P.W. Tucker, and J.P. Allison. 1988. Limited diversity of gamma delta antigen receptor genes of Thy-1+ dendritic epidermal cells. Cell. 55:837-847. http:// dx.doi.org/10.1016/0092-8674(88)90139-0

Augustin, I., V. Goidts, A. Bongers, G. Kerr, G. Vollert, B. Radlwimmer, C. Hartmann, C. Herold-Mende, G. Reifenberger, A. von Deimling, and M. Boutros. 2012. The Wnt secretion protein Evi/Gpr177 promotes glioma tumourigenesis. EMBO Mol. Med. 4:38-51. http:// dx.doi.org/10.1002/emmm.201100186

Bänziger, C., D. Soldini, C. Schütt, P. Zipperlen, G. Hausmann, and K. Basler. 2006. Wntless, a conserved membrane protein dedicated to the secretion of Wnt proteins from signaling cells. Cell. 125:509-522. http://dx.doi.org/10.1016/j.cell.2006.02.049

Barbee, S.D., M.J. Woodward, G. Turchinovich, J.J. Mention, J.M. Lewis, L.M. Boyden, R.P. Lifton, R. Tigelaar, and A.C. Hayday. 2011. Skint-1 is a highly specific, unique selecting component for epidermal $\mathrm{T}$ cells. Proc. Natl. Acad. Sci. USA. 108:3330-3335. http://dx.doi.org/10.1073/ pnas. 1010890108

Bartscherer, K., N. Pelte, D. Ingelfinger, and M. Boutros. 2006. Secretion of Wnt ligands requires Evi, a conserved transmembrane protein. Cell. 125:523-533. http://dx.doi.org/10.1016/j.cell.2006.04.009

Bergboer, J.G., G.S. Tjabringa, M. Kamsteeg, I.M. van Vlijmen-Willems, D. Rodijk-Olthuis, P.A. Jansen, J.Y. Thuret, M. Narita, A. IshidaYamamoto, P.L. Zeeuwen, and J. Schalkwijk. 2011. Psoriasis risk genes of the late cornified envelope-3 group are distinctly expressed compared with genes of other LCE groups. Am. J. Pathol. 178:1470-1477. http:// dx.doi.org/10.1016/j.ajpath.2010.12.017

Billard, M.J., A.L. Gruver, and G.D. Sempowski. 2011. Acute endotoxininduced thymic atrophy is characterized by intrathymic inflammatory and wound healing responses. PLoS ONE. 6:e17940. http://dx.doi.org/ 10.1371/journal.pone.0017940

Blumberg, H., H. Dinh, E.S. Trueblood, J. Pretorius, D. Kugler, N. Weng, S.T. Kanaly, J.E. Towne, C.R. Willis, M.K. Kuechle, et al. 2007. Opposing activities of two novel members of the IL-1 ligand family regulate skin inflammation. J. Exp. Med. 204:2603-2614. http://dx.doi .org/10.1084/jem.20070157

Bonneville, M., R.L. O’Brien, and W.K. Born. 2010. Gammadelta T cell effector functions: a blend of innate programming and acquired plasticity. Nat. Rev. Immunol. 10:467-478. http://dx.doi.org/10.1038/nri2781

Boyden, L.M., J.M. Lewis, S.D. Barbee, A. Bas, M. Girardi, A.C. Hayday, R.E. Tigelaar, and R.P. Lifton. 2008. Skint1, the prototype of a newly identified immunoglobulin superfamily gene cluster, positively selects epidermal gammadelta T cells. Nat. Genet. 40:656-662. http://dx.doi .org/10.1038/ng.108

Cain, D., M. Kondo, H. Chen, and G. Kelsoe. 2009. Effects of acute and chronic inflammation on B-cell development and differentiation. $J$. Invest. Dermatol. 129:266-277. http://dx.doi.org/10.1038/jid.2008.286

Chamcheu, J.C., I.A. Siddiqui, D.N. Syed, V.M. Adhami, M. Liovic, and H. Mukhtar. 2011. Keratin gene mutations in disorders of human skin and its appendages. Arch. Biochem. Biophys. 508:123-137. http://dx.doi .org/10.1016/j.abb.2010.12.019

Chen, D., A. Jarrell, C. Guo, R. Lang, and R. Atit. 2012. Dermal $\beta$-catenin activity in response to epidermal Wnt ligands is required for fibroblast proliferation and hair follicle initiation. Development. 139:1522-1533. http://dx.doi.org/10.1242/dev.076463

Clevers, H., and R. Nusse. 2012. Wnt/ $\beta$-catenin signaling and disease. Cell. 149:1192-1205. http://dx.doi.org/10.1016/j.cell.2012.05.012
De Creus, A., K. Van Beneden, F. Stevenaert, V. Debacker, J. Plum, and G. Leclercq. 2002. Developmental and functional defects of thymic and epidermal V gamma 3 cells in IL-15-deficient and IFN regulatory factor-1deficient mice. J. Immunol. 168:6486-6493.

de Guzman Strong, C., S. Conlan, C.B. Deming, J. Cheng, K.E. Sears, and J.A. Segre. 2010. A milieu of regulatory elements in the epidermal differentiation complex syntenic block: implications for atopic dermatitis and psoriasis. Hum. Mol. Genet. 19:1453-1460. http://dx.doi .org/10.1093/hmg/ddq019

Depianto, D., M.L. Kerns, A.A. Dlugosz, and P.A. Coulombe. 2010. Keratin 17 promotes epithelial proliferation and tumor growth by polarizing the immune response in skin. Nat. Genet. 42:910-914. http://dx.doi.org/ 10.1038/ng.665

Edelbaum, D., M. Mohamadzadeh, P.R. Bergstresser, K. Sugamura, and A. Takashima. 1995. Interleukin (IL)-15 promotes the growth of murine epidermal gamma delta $\mathrm{T}$ cells by a mechanism involving the beta- and gamma c-chains of the IL-2 receptor. J. Invest. Dermatol. 105:837-843. http://dx.doi.org/10.1111/1523-1747.ep12326630

Fu, J., M. Jiang, A.J. Mirando, H.M. Yu, and W. Hsu. 2009. Reciprocal regulation of Wnt and Gpr177/mouse Wntless is required for embryonic axis formation. Proc. Natl. Acad. Sci. USA. 106:18598-18603. http:// dx.doi.org/10.1073/pnas.0904894106

Girardi, M. 2004. Cutaneous biology of gammadelta T cells. Adv. Dermatol. 20:203-215

Goodman, R.M., S. Thombre, Z. Firtina, D. Gray, D. Betts, J. Roebuck, E.P. Spana, and E.M. Selva. 2006. Sprinter: a novel transmembrane protein required for Wg secretion and signaling. Development. 133:49014911. http://dx.doi.org/10.1242/dev.02674

Gordon, J., S. Xiao, B. Hughes III, D.M. Su, S.P. Navarre, B.G. Condie, and N.R. Manley. 2007. Specific expression of lacZ and cre recombinase in fetal thymic epithelial cells by multiplex gene targeting at the Foxn1 locus. BMC Dev. Biol. 7:69. http://dx.doi.org/10.1186/1471-213X-7-69

Gray, E.E., K. Suzuki, and J.G. Cyster. 2011. Cutting edge: Identification of a motile IL-17-producing gammadelta $\mathrm{T}$ cell population in the dermis. $J$. Immunol. 186:6091-6095. http://dx.doi.org/10.4049/jimmunol.1100427

Grzeschik, K.H., D. Bornholdt, F. Oeffner, A. König, M. del Carmen Boente, H. Enders, B. Fritz, M. Hertl, U. Grasshoff, K. Höfling, et al. 2007. Deficiency of PORCN, a regulator of Wnt signaling, is associated with focal dermal hypoplasia. Nat. Genet. 39:833-835. http://dx.doi .org/10.1038/ng2052

Gudjonsson, J.E., A. Johnston, M. Dyson, H. Valdimarsson, and J.T. Elder. 2007. Mouse models of psoriasis. J. Invest. Dermatol. 127:1292-1308. http://dx.doi.org/10.1038/sj.jid.5700807

Hayday, A., and R. Tigelaar. 2003. Immunoregulation in the tissues by gammadelta T cells. Nat. Rev. Immunol. 3:233-242. http://dx.doi.org/ 10.1038/nri1030

Huelsken, J., and W. Birchmeier. 2001. New aspects of Wnt signaling pathways in higher vertebrates. Curr. Opin. Genet. Dev. 11:547-553. http:// dx.doi.org/10.1016/S0959-437X(00)00231-8

Huelsken, J., R. Vogel, B. Erdmann, G. Cotsarelis, and W. Birchmeier. 2001. beta-Catenin controls hair follicle morphogenesis and stem cell differentiation in the skin. Cell. 105:533-545. http://dx.doi.org/10.1016/ S0092-8674(01)00336-1

Jensen, K.B., R.R. Driskell, and F.M. Watt. 2010. Assaying proliferation and differentiation capacity of stem cells using disaggregated adult mouse epidermis. Nat. Protoc. 5:898-911. http://dx.doi.org/10.1038/ nprot.2010.39

Kuraguchi, M., X.P. Wang, R.T. Bronson, R. Rothenberg, N.Y. OheneBaah, J.J. Lund, M. Kucherlapati, R.L. Maas, and R. Kucherlapati. 2006. Adenomatous polyposis coli (APC) is required for normal development of skin and thymus. PLoS Genet. 2:e146. http://dx.doi.org/ 10.1371/journal.pgen.0020146

Leigh, I.M., H. Navsaria, P.E. Purkis, I.A. McKay, P.E. Bowden, and P.N. Riddle. 1995. Keratins (K16 and K17) as markers of keratinocyte hyperproliferation in psoriasis in vivo and in vitro. Br. J. Dermatol. 133:501511. http://dx.doi.org/10.1111/j.1365-2133.1995.tb02696.x

Liu, W., T.M. Shaver, A. Balasa, M.C. Ljungberg, X. Wang, S. Wen, H. Nguyen, and I.B. Van den Veyver. 2012. Deletion of Porcn in mice leads to multiple developmental defects and models human focal dermal 
hypoplasia (Goltz syndrome). PLoS ONE. 7:e32331. http://dx.doi.org/ 10.1371/journal.pone.0032331

Lombardi, M.P., S. Bulk, J. Celli, A. Lampe, M.T. Gabbett, L.B. Ousager, J.J. van der Smaqt, M. Soller, E.L. Stattin, M.A. Mannens, R. Smigiel, and R.C. Hennekam. 2011. Mutation update for the PORCN gene. Hum. Mutat. 32:723-728. http://dx.doi.org/10.1002/humu.21505

Lowes, M.A., A.M. Bowcock, and J.G. Krueger. 2007. Pathogenesis and therapy of psoriasis. Nature. 445:866-873. http://dx.doi.org/10.1038/ nature 05663

Mabuchi, T., T. Takekoshi, and S.T. Hwang. 2011. Epidermal CCR6+ $6 \delta$ $\mathrm{T}$ cells are major producers of IL-22 and IL-17 in a murine model of psoriasiform dermatitis. J. Immunol. 187:5026-5031. http://dx.doi.org/ 10.4049/jimmunol.1101817

Macleod, A.S., and W.L. Havran. 2011. Functions of skin-resident gammadelta T cells. Cell. Mol. Life Sci. 68:2399-2408. http://dx.doi.org/10 .1007/s00018-011-0702-x

McKenzie, R.C., and E. Sabin. 2003. Aberrant signalling and transcription factor activation as an explanation for the defective growth control and differentiation of keratinocytes in psoriasis: a hypothesis. Exp. Dermatol. 12:337-345. http://dx.doi.org/10.1034/j.1600-0625.2003.00100.x

McLelland, B.T., D. Gravano, J. Castillo, S. Montoy, and J.O. Manilay. 2011. Enhanced isolation of adult thymic epithelial cell subsets for multiparameter flow cytometry and gene expression analysis. J. Immunol. Methods. 367:85-94. http://dx.doi.org/10.1016/j.jim.2011.02.008

Mecklenburg, L., M. Nakamura, J.P. Sundberg, and R. Paus. 2001. The nude mouse skin phenotype: the role of Foxn1 in hair follicle development and cycling. Exp. Mol. Pathol. 71:171-178. http://dx.doi.org/10 $.1006 /$ exmp.2001.2386

Myung, P.S., M. Takeo, M. Ito, and R.P. Atit. 2013. Epithelial Wnt ligand secretion is required for adult hair follicle growth and regeneration. J. Invest. Dermatol. 133:31-41. http://dx.doi.org/10.1038/jid.2012.230

Nacken, W., J. Roth, C. Sorg, and C. Kerkhoff. 2003. S100A9/S100A8: Myeloid representatives of the $\mathrm{S} 100$ protein family as prominent player in innate immunity. Microsc. Res. Tech. 60:569-580. http://dx.doi.org/ 10.1002/jemt.10299

Nestle, F.O., D.H. Kaplan, and J. Barker. 2009. Psoriasis. N. Engl. J. Med. 361:496-509. http://dx.doi.org/10.1056/NEJMra0804595

Onoufriadis, A., M.A. Simpson, A.E. Pink, P. Di Meglio, C.H. Smith, V. Pullabhatla, J. Knight, S.L. Spain, F.O. Nestle, A.D. Burden, et al. 2011. Mutations in IL36RN/IL1F5 are associated with the severe episodic inflammatory skin disease known as generalized pustular psoriasis. Am. J. Hum. Genet. 89:432-437. http://dx.doi.org/10.1016/j.ajhg.2011.07.022

Osada, M., L. Jardine, R. Misir, T. Andl, S.E. Millar, and M. Pezzano. 2010. DKK1 mediated inhibition of Wnt signaling in postnatal mice leads to loss of TEC progenitors and thymic degeneration. PLoS ONE. 5:e9062. http://dx.doi.org/10.1371/journal.pone.0009062

Pittelkow, M.R. 2005. Psoriasis: more than skin deep. Nat. Med. 11:17-18. http://dx.doi.org/10.1038/nm0105-17

Proksch, E., J.M. Brandner, and J.M. Jensen. 2008. The skin: an indispensable barrier. Exp. Dermatol. 17:1063-1072. http://dx.doi.org/10.1111/ j.1600-0625.2008.00786.x

Reischl, J., S. Schwenke, J.M. Beekman, U. Mrowietz, S. Stürzebecher, and J.F. Heubach. 2007. Increased expression of Wnt5a in psoriatic plaques. J. Invest. Dermatol. 127:163-169. http://dx.doi.org/10.1038/sj.jid .5700488

Roberson, E.D., and A.M. Bowcock. 2010. Psoriasis genetics: breaking the barrier. Trends Genet. 26:415-423. http://dx.doi.org/10.1016/j.tig.2010 .06 .006

Romanowska, M., A. Evans, D. Kellock, S.E. Bray, K. McLean, S. Donandt, and J. Foerster. 2009. Wnt5a exhibits layer-specific expression in adult skin, is upregulated in psoriasis, and synergizes with type 1 interferon PLoS ONE. 4:e5354. http://dx.doi.org/10.1371/journal.pone.0005354

Sabat, R., S. Philipp, C. Höflich, S. Kreutzer, E. Wallace, K. Asadullah, H.D. Volk, W. Sterry, and K. Wolk. 2007. Immunopathogenesis of psoriasis. Exp. Dermatol. 16:779-798. http://dx.doi.org/10.1111/j.1600-0625 .2007.00629.x

Sadik, C.D., N.D. Kim, and A.D. Luster. 2011. Neutrophils cascading their way to inflammation. Trends Immunol. 32:452-460. http://dx.doi .org/10.1016/j.it.2011.06.008

Sano, S., K.S. Chan, S. Carbajal, J. Clifford, M. Peavey, K. Kiguchi, S. Itami, B.J. Nickoloff, and J. DiGiovanni. 2005. Stat3 links activated keratinocytes and immunocytes required for development of psoriasis in a novel transgenic mouse model. Nat. Med. 11:43-49. http://dx.doi .org/10.1038/nm1162

Schlake, T. 2001. The nude gene and the skin. Exp. Dermatol. 10:293-304. http://dx.doi.org/10.1034/j.1600-0625.2001.100501.x

Schlake, T., and S. Sick. 2007. Canonical WNT signalling controls hair follicle spacing. Cell Adhes. Migr. 1:149-151. http://dx.doi.org/10.4161/cam .1.3.5073

Schön, M., D. Denzer, R.C. Kubitza, T. Ruzicka, and M.P. Schön. 2000. Critical role of neutrophils for the generation of psoriasiform skin lesions in flaky skin mice. J. Invest. Dermatol. 114:976-983. http://dx.doi.org/ 10.1046/j.1523-1747.2000.00953.x

Schwenk, F., U. Baron, and K. Rajewsky. 1995. A cre-transgenic mouse strain for the ubiquitous deletion of loxP-flanked gene segments including deletion in germ cells. Nucleic Acids Res. 23:5080-5081. http:// dx.doi.org/10.1093/nar/23.24.5080

Semprini, S., F. Capon, A. Tacconelli, E. Giardina, A. Orecchia, R. Mingarelli, T. Gobello, G. Zambruno, A. Botta, G. Fabrizi, and G. Novelli. 2002. Evidence for differential S100 gene over-expression in psoriatic patients from genetically heterogeneous pedigrees. Hum. Genet. 111:310-313. http://dx.doi.org/10.1007/s00439-002-0812-5

Seung, N.R., E.J. Park, C.W. Kim, K.H. Kim, K.J. Kim, H.J. Cho, and H.R. Park. 2007. Comparison of expression of heat-shock protein 60, Toll-like receptors 2 and 4 , and T-cell receptor gammadelta in plaque and guttate psoriasis. J. Cutan. Pathol. 34:903-911. http://dx.doi.org/10 $.1111 / \mathrm{j} .1600-0560.2007 .00756 . \mathrm{x}$

Soza-Ried, C., C.C. Bleul, M. Schorpp, and T. Boehm. 2008. Maintenance of thymic epithelial phenotype requires extrinsic signals in mouse and zebrafish. J. Immunol. 181:5272-5277.

Sumaria, N., B. Roediger, L.G. Ng, J. Qin, R. Pinto, L.L. Cavanagh, E. Shklovskaya, B. Fazekas de St Groth, J.A. Triccas, and W. Weninger. 2011. Cutaneous immunosurveillance by self-renewing dermal $\gamma \delta \mathrm{T}$ cells. J. Exp. Med. 208:505-518. http://dx.doi.org/10.1084/jem.20101824

Swindell, W.R., A. Johnston, S. Carbajal, G. Han, C. Wohn, J. Lu, X. Xing, R.P. Nair, J.J. Voorhees, J.T. Elder, et al. 2011. Genome-wide expression profiling of five mouse models identifies similarities and differences with human psoriasis. PLoS ONE. 6:e18266. http://dx.doi.org/ 10.1371/journal.pone.0018266

Wagner, E.F., H.B. Schonthaler, J. Guinea-Viniegra, and E. Tschachler. 2010. Psoriasis: what we have learned from mouse models. Nat Rev Rheumatol. 6:704-714. http://dx.doi.org/10.1038/nrrheum.2010.157

Waseem, A., B. Dogan, N. Tidman, Y. Alam, P. Purkis, S. Jackson, A. Lalli, M. Machesney, and I.M. Leigh. 1999. Keratin 15 expression in stratified epithelia: downregulation in activated keratinocytes. J. Invest. Dermatol. 112:362-369. http://dx.doi.org/10.1046/j.1523-1747.1999 $.00535 . \mathrm{x}$

Yano, S., T. Banno, R. Walsh, and M. Blumenberg. 2008. Transcriptional responses of human epidermal keratinocytes to cytokine interleukin-1. J. Cell. Physiol. 214:1-13. http://dx.doi.org/10.1002/jcp.21300 